\title{
ARTICLE OPEN \\ Coupled flow accumulation and atmospheric blocking govern flood duration
}

\author{
Nasser Najibi (iD) ${ }^{1,2,3}$, Naresh Devineni (iD), Mengqian Lu (iD ${ }^{4}$ and Rui A. P. Perdigão (iD $5,6,7$
}

We present a physically based Bayesian network model for inference and prediction of flood duration that allows for a deeper understanding of the nexus of antecedent flow regime, atmospheric blocking, and moisture transport/release mechanisms. Distinct scaling factors at the land surface and regional atmospheric levels are unraveled using this Bayesian network model. Land surface scaling explains the variability in flood duration as a function of cumulative exceedance index, a new measure that represents the evolution of the flood in the basin. Dynamic atmospheric scaling explains the cumulative exceedance index using the interaction between atmospheric blocking system and the synergistic model of wind divergence and atmospheric water vapor. Our findings underline that the synergy between a large persistent low-pressure blocking system and a higher rate of divergent wind often triggers a long-duration flood, even in the presence of moderate moisture supply in the atmosphere. This condition in turn causes an extremely long-duration flood if the basin-wide cumulative flow prior to the flood event was already high. Thus, this new landatmospheric interaction framework integrates regional flood duration scaling and dynamic atmospheric scaling to enable the coupling of 'horizontal' (for example, streamflow accumulation inside the basin) and 'vertical' flow of information (for example, interrelated land and ocean-atmosphere interactions), providing an improved understanding of the critical forcing of regional hydroclimatic systems. This Bayesian model approach is applied to the Missouri River Basin, which has the largest system of reservoirs in the United States. Our predictive model can aid in decision support systems for the protection of national infrastructure against long-duration flood events.

npj Climate and Atmospheric Science (2019)2:19; https://doi.org/10.1038/s41612-019-0076-6

\section{INTRODUCTION}

The consequences of long-term inundation of floodplains, residential and commercial areas, and critical infrastructure cannot be fully comprehended without a clear understanding of the variability in the duration of the floods. ${ }^{1-3}$ Analysis of flood frequency is commonly based on the use of instantaneous peak flow; however, the impacts of floods may not be determined exclusively by its instantaneous peak value. ${ }^{4}$ For example, during the recent floods that occurred in Pakistan (Indus River Basin in late July 2010), Australia (Queensland in December 2010), Germany (the Danube and Elbe Basins in June 2013), the United States of America (Colorado in September 2013), Thailand (July 2011 and December 2014), and South India (Chennai in November 2015), the damage to residential areas and industries, and consequently the disruption of the global supply chain was associated more with long-duration floods than the instantaneous peak flow of the flood event. ${ }^{5-10}$ There is a dearth of literature that focuses on the duration of the floods, their variability, and their association with catchment-scale factors and dominant synoptic to large-scale ocean-atmospheric drivers. Quantifying the relations of flood duration to these multi-level drivers will significantly advance the science of multi-scale flood risk assessment and critical infrastructure maintenance (e.g., flood control systems).
This knowledge will help in achieving reliable climatic risk adaptation strategies for the twenty-first century. ${ }^{11}$

Initial basin-wide wetness and anomalous precipitation that is driven by large-scale atmospheric teleconnections typically manifest in the duration of the floods that can last from days to months. ${ }^{12}$ The relative wetness of the catchment before a flood event can be a significant factor in defining the type of the flood; such as short duration high-intensity flood or long duration moderate intensity flood. ${ }^{13}$ Often, this catchment behavior overrides the climate and meteorological conditions in predicting the flood. ${ }^{14}$ For instance, the combination of a moderate rainfall event in June 2013 with extreme preceding land wetness conditions caused an unusual mega-flood in south and east of Germany in June-July 2013. ${ }^{9}$ The substantial role of land wetness conditions in regulating the magnitude of design floods has also been demonstrated by analyzing the dependence between simultaneous rain events and antecedent wetness states in the Murray-Darling Basin. ${ }^{15}$ Similarly, in our recent work, ${ }^{12}$ we have found that the flood events with durations longer than 30 days were attributed to greater antecedent flow conditions. This high antecedent flow condition (a flow rate exceeding the flood stage) in conjunction with the concurrent rainfall events (moderate or high intensity) was causing large flood volumes in the reservoirs. ${ }^{12}$

\footnotetext{
${ }^{1}$ Department of Civil Engineering, City University of New York (City College), New York, NY 10031, USA; ${ }^{2}$ Center for Water Resources and Environmental Research (City Water Center), City University of New York, New York, NY 10031, USA; ${ }^{3}$ NOAA/Cooperative Science Center for Earth System Sciences and Remote Sensing Technologies (CREST), City University of New York, New York, NY 10031, USA; ${ }^{4}$ Department of Civil and Environmental Engineering, The Hong Kong University of Science and Technology, Clear Water Bay, Kowloon, Hong Kong, SAR, China; Institute of Telecommunications, Physics of Information and Quantum Technologies Group, Lisbon, Portugal; ${ }^{6} \mathrm{Centre}$ for Ecology, Evolution and Environmental Changes, Faculty of Sciences, University of Lisbon, Lisbon, Portugal and ${ }^{7}$ Meteoceanics Interdisciplinary Centre for Complex System Science \& Technische Universtät Wien (TU Wien), Vienna, Austria

Correspondence: Nasser Najibi (nnajibi@ccny.cuny.edu)
}

Received: 13 September 2018 Accepted: 28 May 2019

Published online: 20 June 2019 
While antecedent flow conditions play a major role in explaining the duration of the flood, it is not an exclusive causal variable. In addition to the initial land wetness conditions, unusually large flood events require recurrent moisture transport from oceanic sources and an organized atmospheric blocking system. ${ }^{16,17}$ It has been shown recently that synoptic to large-scale atmospheric conditions associated with major flood events seem to be well correlated with moisture transport from oceanic sources. ${ }^{18,19}$ Further, these large-scale atmospheric conditions also contribute to anomalous antecedent flow conditions and rainfall intensity. ${ }^{12}$ While individual atmospheric rivers (ARs) may not necessarily cause a flood due to the rapid propagation over the basin, ${ }^{20}$ a well-established system of atmospheric blocking leads to a stationary weather pattern over a large area, thus enabling the interaction of the low-level frontal zone with the upper-level tracks. This phenomenon is defined as "thunderstorm training at the cyclonic scale" where the atmospheric setup leads to continuous downpours. ${ }^{21,22}$ These quasi-stationary synoptic-tolarge-scale tropospheric blocking systems modulate regional climatic features across the mid-latitudes by setting up monotonous weather proxies over the locations under the block and its surroundings. ${ }^{23}$ In addition, they regulate the westerly winds by suppressing the eastward progression of extratropical synoptic disturbances. $^{24}$ The blocking over the mid-latitudes is linked to a zonal pressure fluctuation mechanism between the Baltic and Greenland, termed Baltic-Greenland Oscillation (BGO). BGO is unveiled from an information-theoretic spatiotemporal decomposition of the low-frequency geopotential height fields at 500 $[\mathrm{hPa}]$ and retrieved from dynamical systems analytics as the Zonal Dynamic Source of synoptic-scale extratropical atmospheric variability in the Northern Hemisphere. ${ }^{25,26}$ Essentially, the BGO suppresses, counterbalances or enhances the zonal flow thereby being responsible for increasing or reducing the atmospheric blocking risk.

We have seen evidence for such organized phenomena leading to significant flooding in Pakistan in 2010, Fort Collins, Colorado in 1997, and across the entire state of Colorado in 2013. In Pakistan, an enhanced upward air motion (intense long-lived divergent system aloft) was followed by the tropical moisture flux and extratropical low-frequency waves in the troposphere. ${ }^{27,28}$ This process contributed to heavy rainfall events. ${ }^{27,28}$ The coexistence of both moist cyclonic storms and quasi-stationary convective pressure systems (i.e., negative pressure ridge with divergent forcing associated with a shortwave trough over the area) generated a record-setting precipitation, and ultimately, a devastating flood in Fort Collins (CO, United States) in July 1997. ${ }^{29}$ Similarly, analysis of the "Great Colorado flood" in September 2013 also indicates that the standardized anomalies of precipitable water content (PWC) were two to four times higher than the norm across a large corridor extending from the Gulf of Mexico and the tropical eastern Pacific towards the Intermountain West. ${ }^{7}$ This was caused by a strong jet-stream moisture transport fed by the broader-scale anomalous oceanic conditions (mostly in the Western Hemisphere tropical oceans) where the geopotential height (GPH) anomalies were also abnormally large. ${ }^{7}$ The persistence of regional cyclonic structures locked in-phase by planetary wave blocking, further enhanced by high antecedent soil moisture, has also been found ${ }^{30}$ to trigger widespread flooding in Central Europe, e.g. in 1954, 2002, and 2013. There, a synoptically locked in-phase Central European cyclonic pattern, termed $\mathrm{Vb}$, drove atmospheric moisture from over the Mediterranean into a cyclonic track fueling heavy and persistent precipitation over Central Europe, contributing significantly to the flooding that ensued. ${ }^{30}$

As mentioned through these illustrative examples, preceding flow accumulation and concurrent atmospheric features can potentially represent the drove for explaining the variability of the flood duration. Our central focus is to explain how the flood duration scales with antecedent flows conditioning and atmospheric features, which are the primary contributing factors originating from the coupled land-ocean-atmosphere dynamic system. In this study, we summarize these leading factors as maximum cumulative exceeding flow (referred to as the cumulative exceedance index, CEI, hereafter), blocking systems of pressure in the atmosphere (anomalous patterns of GPH), sufficient amount of moisture supply (water vapor), and the converging process for the available moisture (divergent wind) to flood duration. Although these factors have been individually known to contribute to floods for several years, their relation to persistent anomalous blocking patterns and linking mechanisms between the preceding flow regime, moist air masses, and blocking patterns have remained obscure. To this extent, this advanced analysis of land-atmosphere-ocean dynamics and their interactions to quantify "flood duration" is developed, and applied to the Missouri River Basin (MRB). We selected the MRB since it has the largest system of reservoirs in the United States (Supplementary Fig. 1) with a total storage capacity of 74 million acre-feet and a surface area of one million acres. ${ }^{31}$ Also, it has been shown in previous studies ${ }^{19}$ that there is a potential link between the oceanic moisture source(s) and the regional precipitation regimes and streamflows for large river basins. The MRB encompasses $529,350 \mathrm{mi}^{2}$ over ten states (Colorado, lowa, Kansas, Minnesota, Missouri, Montana, Nebraska, North Dakota, South Dakota, and Wyoming), and drains one-sixth of America's land. The Missouri River flows for about 2341 miles across these ten states to reach its confluence point at the Mississippi River north of St. Louis (MO, United States).

\section{RESULTS AND DISCUSSION}

Examples of individual contributions of flow accumulation and atmospheric dynamics to flood duration

This section explores, on an event-specific basis, how the coupled influence of various processes can affect flood duration. These examples highlight the complex, event-specific nature of processes driving flood duration and motivate the application and need for a framework to unify and quantify the various processes beyond event-specific analysis. In Fig. 1a, we present a diagram of how the initial flow fraction at a time $i\left(\mathrm{Qf}_{\mathrm{i}}\right)$ preceding the flood peak triggers floods of various durations-long (floods greater than or equal to 21 days), moderate (floods lasting more than 1 week up to 3 weeks), and short (floods lasting less than a week) (see the computation of $\mathrm{Qf}_{\mathrm{i}}$ in the Methods section). This classification of the flood duration is consistent with the one employed by the Dartmouth Flood Observatory (DFO) for riverine flooding measurements using satellite imagery products. ${ }^{32}$ There can be instances or events where the $Q f_{i}$ can be close to, or greater than 1 (a filled river condition prior to the flood) and continues to increase with succeeding rainfall events to create a flood of long duration; termed here a long-duration flood. This long-duration flood scenario may be associated with a high flood peak and can take several days or weeks to recede. The moderateduration floods can have close-to-filled river conditions prior to the flood $\left(\mathrm{Qf}_{\mathrm{i}}\right.$ less than, or close to 1$)$, and depending on whether or not the following rainfall events are persistent, will lead to moderate peaks and fast recession; termed here a moderateduration flood scenario. Contrary to the long and moderateduration floods, the short-duration floods may be associated with empty river conditions preceding the flood (small or close to $0 \mathrm{Qf}_{\mathrm{i}}$ ) that can absorb all the succeeding rainfall, causing a flood of short duration; short-duration flood scenario. Next, Fig. 1b shows the time series of $\mathrm{Qf}_{\mathrm{i}}$ on the primary $y$-axis and the cumulative exceeding flow on the secondary $y$-axis from T-37 to $T$, the time of the flood. The daily cumulative exceedance of the flow fraction $\mathrm{Qf}_{\mathrm{i}}$ is measured with respect to $Q f=1$, the critical streamflow 

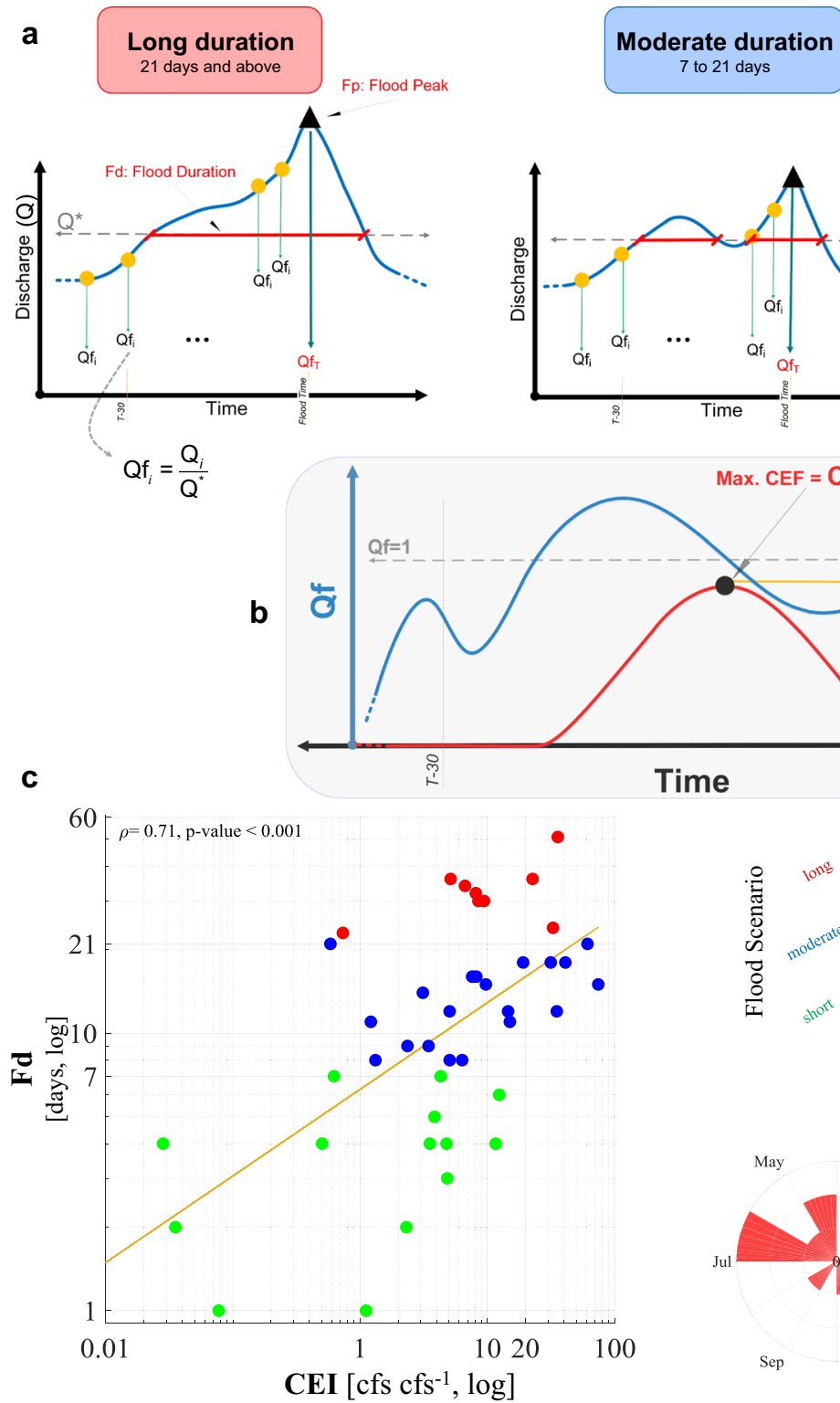

Short duration 7 to 21 days

Less than 7 days
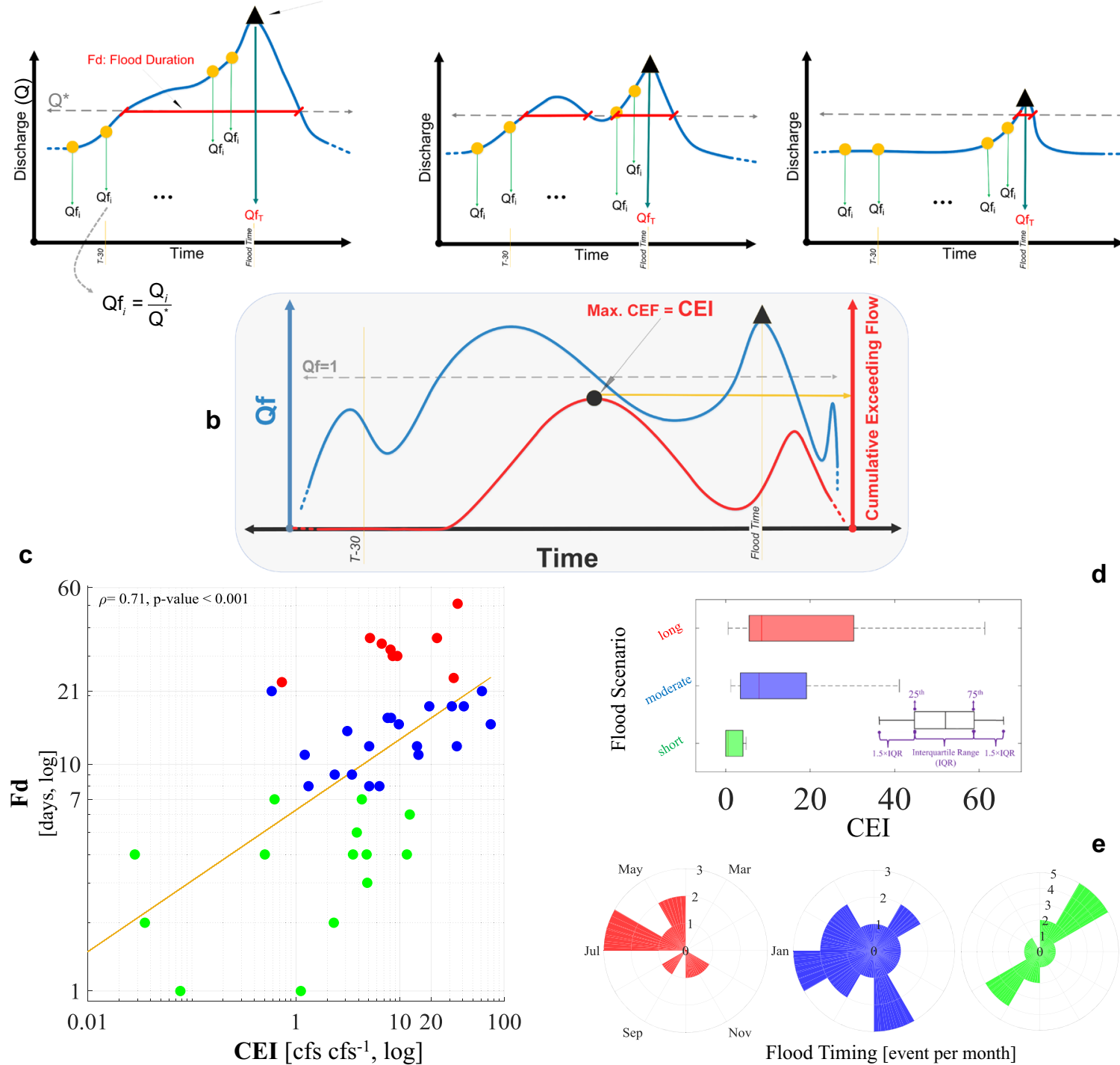

Fig. 1 Flood duration regulated by antecedent exceeding flow regime changes. The steady (unsteady) increase of large (small) initial flow fractions $\left(\mathrm{Qf}_{\mathrm{i}}\right)$ a and maximum antecedent cumulative exceeding flow index (CEI) $\mathbf{b}$ is determining a specific flood duration scenario. A significant relationship exists between CEI and Fd (c) and larger CEl values induce a longer duration flood d. The long-duration floods also occur during certain seasons (blocks) of the year e

threshold for flood. The maximum cumulative exceeding flow is considered as the cumulative exceedance index of flow (CEI), the total accumulation of the flow (relative to the threshold) preceding and up to the flood peak. The CEI can serve as a good indicator of the duration of the flood. A low CEI is an indication of a non-flood condition in the river/reservoir. A high CEI indicates filling up of the river due to threshold exceedance flow, thus leading to a long-duration flood.

To illustrate the dependence of flood duration on CEl, we present in Fig. 1c, the log-log pairwise scatterplot of CEI and flood duration ( $\mathrm{Fd}$ ) for the 49 years of data available in the MRB over five large reservoirs. CEI is estimated as the maximum cumulative exceeding flow using the daily flow fractions $\left(\mathrm{Qf}_{\mathrm{i}}\right)$ for the 37 days preceding the flood peak (see the Methods section for a detailed explanation of the approach). Short, moderate and long-duration floods are shown in green, blue, and red colored filled circles respectively. Pearson's correlation coefficient between the two variables is 0.71 . In Fig. 1d, we present the distributions of CEI for each case of the short, moderate and long-duration floods. We can see a clear separation between the short-duration floods with a median CEl equal to 0.56 (the state of empty river condition), and long-duration floods with a median CEI equal to 8.51 (the state of a relatively full river condition). The moderate flood duration events are in between the short and long-duration flood events. While the median CEI values for the moderate and the long duration floods are comparable, the long duration events clearly exhibit a skewed distribution with a heavy tail, indicating their association with large CEI. The flood events associated with long, moderate, and short-duration scenarios have a mean CEI of 17.4, 15.8, and $2.5\left(\mathrm{cfs} \mathrm{cfs}^{-1}\right.$ ) respectively. The histogram chart derived from the time of flood occurrence in polar coordinates (Fig. 1e) indicates that peak flood mostly occurs between April and June for the long-duration floods. Conversely, it is much more spreadout through the year for the moderate-duration floods. For the short-duration floods, we find most of the events occurring in February and August. The dependence of flood duration on the 

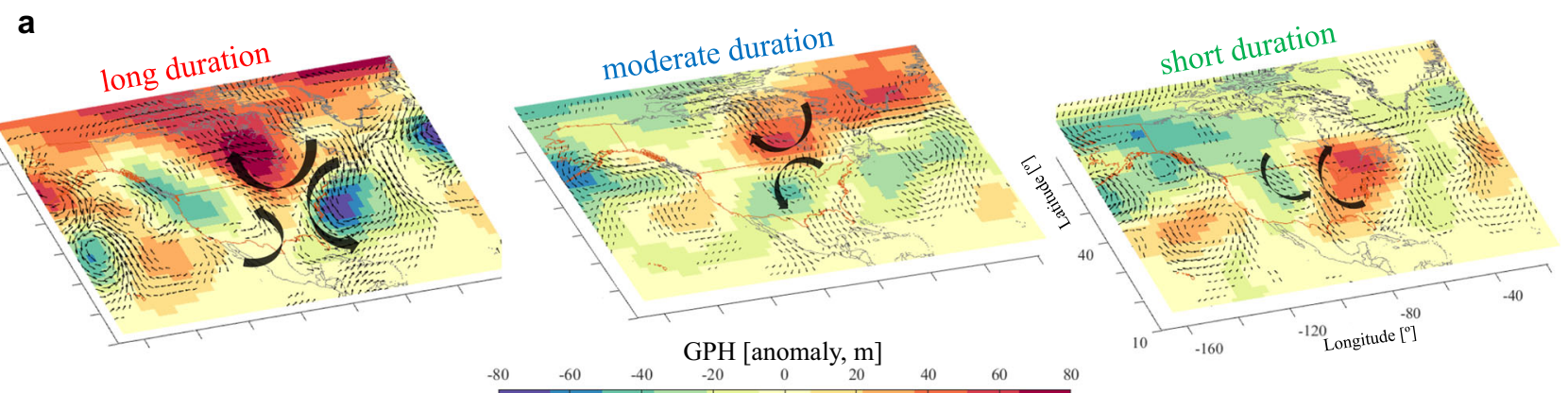

b
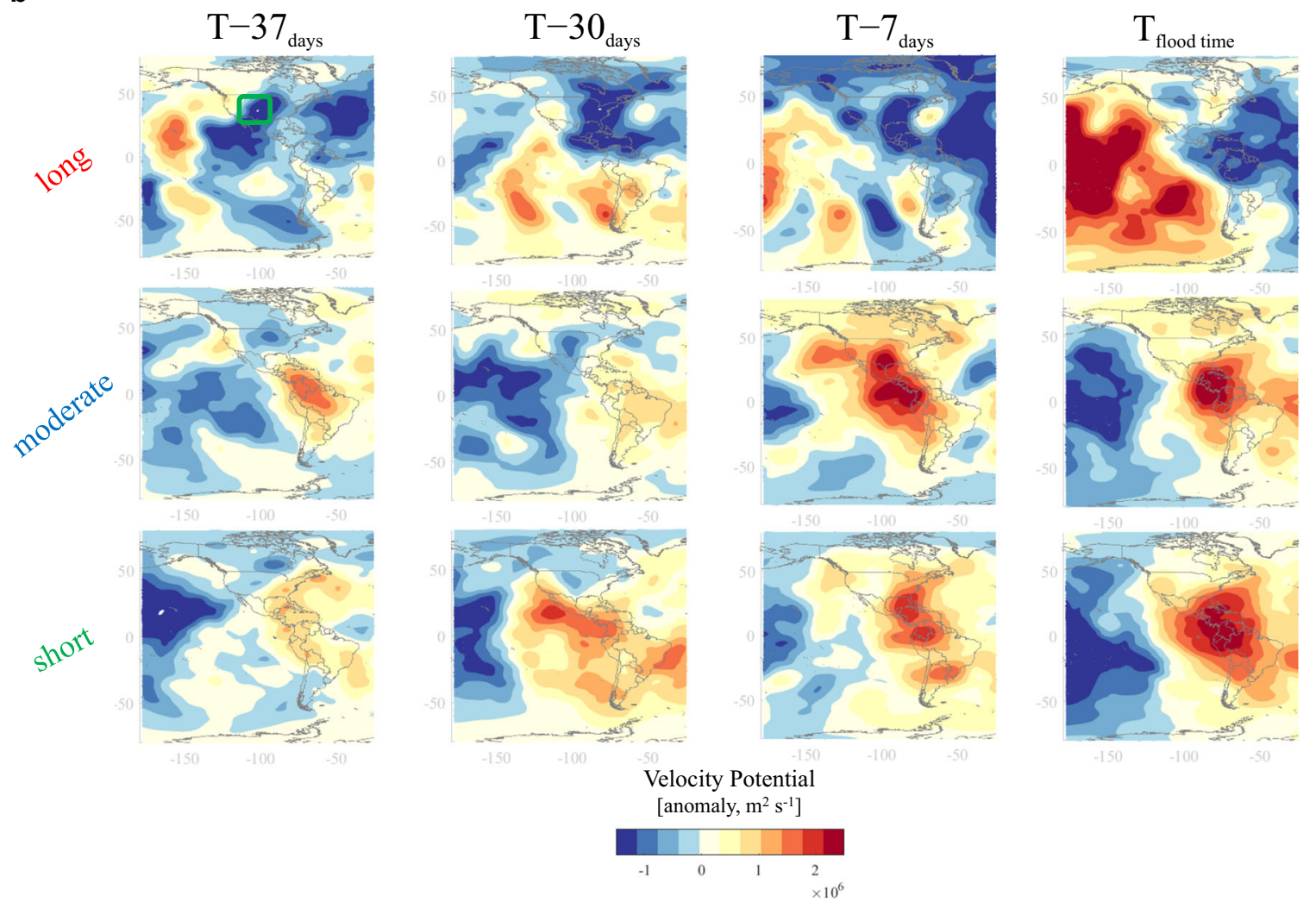

Fig. 2 Large-scale systems of atmospheric blocking pressure and system of divergent wind. The Geopotential Height (GPH) anomalies with significant wind vectors at $500 \mathrm{mb}$ a and velocity potential anomalies at 0.2582 sigma level $\mathbf{b}$ for floods with long, moderate, and short durations (1966-2014). Vertical movement of warm moist air is continuously occurring for longer duration flood events 37, 30, and 7 days preceding the flood, and on the day of the flood event

preceding flow accumulation suggests a general association that can be employed in a quantitative model for explaining how the duration of the flood scales in relation to the CEI (Fig. 1b, c).

In addition to the preceding flow accumulation, the antecedent atmospheric circulation and the associated proxies of large-scale upward air motions are also crucial factors determining the flood durations, as suggested by various studies mentioned previously. Hence, we investigated the regional atmospheric circulation over the basin for any significant patterns and control features that can explain the long-duration floods. Figure $2 a$ shows the composite pattern of the GPH anomalies at $500 \mathrm{mb}$ pressure level during the days of peak flood for the long, moderate and short-duration floods, respectively. These height anomalies primarily represent the intensity of the upper-level trough and can be used to understand the states of convergence/divergence patterns that emerge from the low-frequency atmospheric flow aloft along the Rossby wave. ${ }^{19}$ The top fiftieth percentile wind fields are also plotted along with the GPH anomaly composite.
For the long-duration flood scenario, we see a notable low-highlow pattern of GPH anomalies-an Omega blocking ${ }^{22}$ - which is significantly positive to the east of the MRB together with a strong negative anomaly stretch over the tropical Atlantic Ocean, and a weak negative over the western parts of the basin (Fig. 2a: long). The Omega blocking configuration over the basin essentially acts as a stationary trap for the eastward-to-poleward air circulations while unsettled and stormy weather is situated under the lowpressure fields for an extended period. This atmospheric blocking acts as the necessary condition for recurrent rainfall events in the region. ${ }^{33}$ The spatial pattern of the GPH anomalies for the moderate-duration scenario reveals a Rex blocking mechanism ${ }^{21}$ where the poleward positive anomalies settle immediately to the north of a weak high-pressure across the Great Plains and southern Great Lakes of North America (Fig. 2a: moderate). In the short-duration flood scenario, a weak high-pressure zone extends over most parts of the MRB-dry condition-while a weak lowpressure area appears far away from the MRB towards the tropical 
Atlantic Ocean (Fig. 2a: short). The latter system substantially shortens the stay of moist air above the MRB, which precludes the available water vapor (if any) to be released as precipitation, and subsequently, the surface flow rate lessens towards reaching a dry condition. These spatial patterns of the GPH anomalies are also significant for a seven-day interval advancing the flood events (T-7 to $\mathrm{T}$ ) in each flood-duration scenario (Supplementary Fig. 2).

The composites of velocity potential (VP) anomalies at 0.2582 sigma level are presented for each of the long, moderate, and short-duration floods in Fig. 2b. These composites are plotted for 37 days (left panel), 30 days (center left panel), 7 days (center right panel) preceding the flood peak and for the day of the flood (right panel) to investigate the evolution of (anti)cyclonic system that interacts with the existing moisture over the basin. We chose VP anomalies at 0.2582 sigma level to evaluate the persistence and behavior of turbulence (if any) within the upper atmospheric level considered in the study. The other sigma levels in the reanalysis project correspond to either the near-surface layer or far-above atmosphere layer. The VP anomalies can be used to track the regions of upper-level divergence. Negative (positive) velocity potential anomalies represent divergence (convergence) aloft, i.e., the regions where convection is enhanced (suppressed). For long-duration flood scenario, Fig. $2 \mathrm{~b}$ shows sustained strong negative VP anomalies (persistent low-pressure organization) spreading out over the MRB during the preceding days to the current day, leading to continuous regional moisture convergence that enhances the land wetness conditions (i.e., increases the Qf) and ultimately causes a long-duration flood event. In fact, large negative VP anomalies, also referred to as the cyclonic mode, propel more divergent wind in the upper-level atmosphere. This phenomenon eventually strengthens the lifting mechanism for the column of moist air-causing precipitation.

The absolute values of divergent winds-which are proportional to the gradient of $\mathrm{VP}^{34}$-for long-duration floods are significantly larger (with VP around $-1.5 \times 10^{6} \mathrm{~m}^{2} \mathrm{~s}^{-1}$ ) than those in moderate $\left(-0.5 \times 10^{6} \mathrm{~m}^{2} \mathrm{~s}^{-1}\right)$ and short durations $\left(-0.1 \times 10^{6}\right.$ $\mathrm{m}^{2} \mathrm{~s}^{-1}$ ) (Fig. 2b). Since there is a strong vertical ascent of warm moist air where the negative VP anomalies are large, this vertical motion of air is linked to the departure of atmospheric steadystate from the geostrophic balance that governs the large-scale air movement in the atmosphere (Fig. 2b: long). Ultimately, this instability would release the thermally driven turbulent energies, leads to adiabatic cooling, cumuliform cloud formation, and intense precipitation ahead of the fronts. This 'elevated convection' will take place repeatedly until reaching a stable condition at the tropospheric level.

Conversely, when the convergence of moist air occurs in the upper troposphere with divergence at the lower level (positive VP anomalies), it is hypothesized that this results in the downward motion of air-downslope convection-and absence of potential precipitation events. This pattern is seen predominantly in the short-duration floods (Fig. 2b: short). For both moderate and short-duration flood events, we observe that the 37-day preceding pattern starts off with moisture convergence (Fig. 2b left and center-left panel: moderate and short). However, as we approach the flood events (7-day to current day) (Fig. 2b center-right and right panel: moderate and short), the VP anomalies turn positive, indicating that the precipitation is not sustained all the way to the peak flow day. Hence there is a fast recession of the flood in the river, leading to only moderate or short durations.

Figure $3 a$ shows the contributing moisture trajectories for three example flood events corresponding to long, moderate, and shortduration floods in the MRB. The selected flood events are all associated with the Tropical Moisture Exports (TMEs). The three panels show all the contributing TME tracks that entered the MRB between 37 and 7 days before the flood occurrence. They illustrate the building up process for moisture convergence that sets up the cumulative exceedance conditions that are in turn linked to the variability of Fd in MRB. TMEs for several other flood events for long, moderate, and short-duration scenarios are shown in Supplementary Fig. 3.

While the local frontal convergence and pressure gradients would promote the occurrence of extreme rainfall, most of the heavy (and/or frequent) precipitation events can be related to intense (and/or prolonged) horizontal water vapor transport (measured by the vertically Integrated Vapor Transport or $\mathrm{IVT}^{35}$ ). To better understand the moisture delivery during these events, we have calculated the IVT at the global scale and presented it as a 37-day time series in Fig. 3b corresponding to the three flood events indicated in Fig. 3a. The 37-day time series of IVT accounts for enough time to understand the lagged-relationship between the transported water vapor, changes in the initial flow fraction, and eventually the duration of the flood (long, moderate, or short durations). Our analyses reveal that for a 36-day flood event that occurred on May 15, 1999 (red-colored frame in Fig. 3b), the MRB was frequently a destination of $120 \mathrm{~kg} \mathrm{~m}^{-1} \mathrm{~s}^{-1}$ vapor transport for 6 days (see the six thicker black-colored hollow boxes in Fig. 3b, from T-37 days to T-32 days) (Fig. 3b). This organized system of vapor transport was associated with the extratropical cyclones originated around $150-160^{\circ} \mathrm{W}$. Such an organized pattern does not exist for a moderate flood duration that occurred on September 13, 2008 (i.e., blue-colored frame in Fig. 3b). The IVT features for this 8-day flood event reveal the occurrence of Atlantic hurricane with a significant IVT trajectory adjacent to the MRB from T-12 to T-10 (i.e., three thicker black hollow boxes within the green-colored frame in Fig. 3b). In contrast, the 37-day time series of IVT for a one-day flood that occurred in October 1980 pointed a single day substantial vapor transport from the lower latitudes towards the MRB. Assessing these three flood durations using the IVT properties reveal that a prolonged and intensified system of vapor transport might define the regional differences in the flood durations, and a more nuanced investigation of different causes of the flood duration is necessary.

Figure $4 a$ outlines schematically, the control mechanisms involved, i.e., the oceanic moisture sources, upper-tropospheric atmospheric pressure systems (which feature as blocking) and wind divergence/convergence aloft, and regional surface level (anti)cyclonic forces. We further assessed the sink-source characteristics and space-time structure of the tropical moisture transport that trigger $\mathrm{CEI}$ and $\mathrm{Fd}$. Figure $4 \mathrm{~b}$ presents the spacetime climatology of the moisture sources for the MRB using the Tropical Moisture Exports (TMEs) dataset (1979-2013). ${ }^{36}$ The left panel of Fig. 4b shows that the Gulf of Mexico (GP; one of the global TMEs moisture source hotspots defined by ${ }^{36}$ ) is the primary moisture source for the MRB during the wet (flood) season from May to August. This seasonal feature, i.e., the intra-annual variation is shown in the right panel. Some winter contribution from another global moisture hotspot, the Pineapple Express (PE) region ${ }^{36}$ is also observed, indicating enhanced westerly in the wintertime. The inflow of moist air masses from the Gulf of Mexico towards the central parts of the United States is a feature of the North American monsoon system ${ }^{36}$ associated with the Great Plains low-level jet (GPLL). The GPLLJ transports around one-third of the moisture to the central United States from the Gulf of Mexico. ${ }^{37}$ It links the large-scale circulation disturbances with regional climate proxies and regulates the intensity and longevity of mesoscale convective complexes across the central United States. ${ }^{38}$ In our previous studies on climate extremes in various regions across the United States and Europe, ${ }^{12,18,39}$ we have also identified the Gulf of Mexico as a dominant source of moisture inflow. For instance, a statistical and physical framework linking extreme precipitation in the Northeast United States to its origin in the Gulf of Mexico is put forward in ref. ${ }^{39}$ Another study conducted by ${ }^{18}$ for Western Europe shows that the rainfall which caused a 100-year flood in January 1995 was fueled by consistent moisture transport from the GP region with a persistent large-scale near-stationary planetary 
a

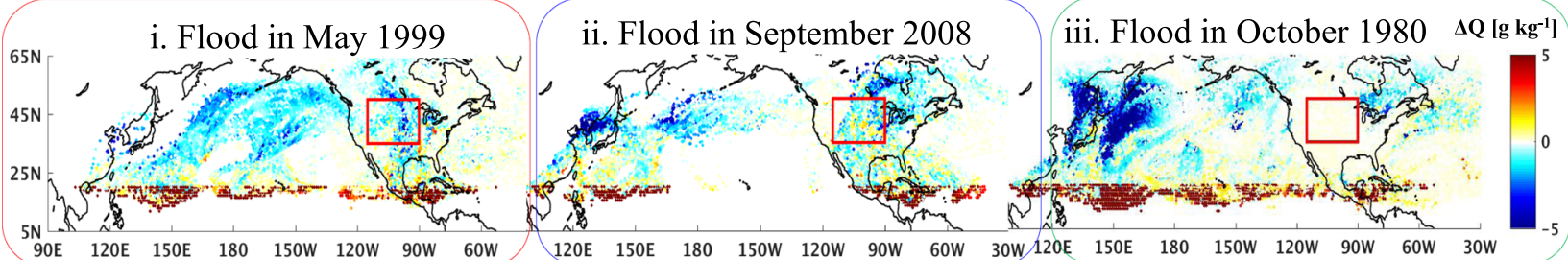

b
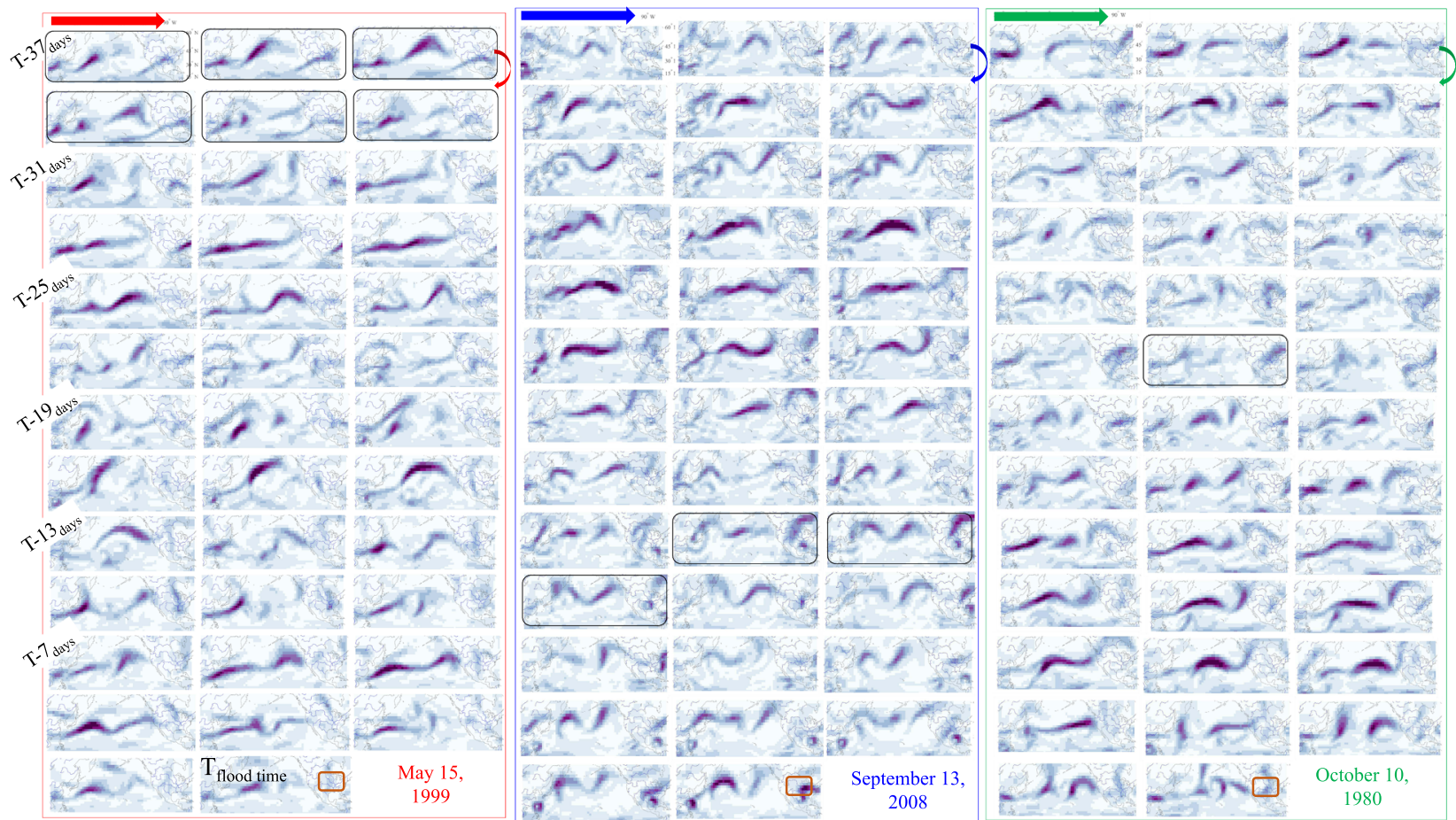

IVT $\left[\mathrm{kg} \mathrm{m}^{-1} \mathrm{~s}^{-1}\right]$

$\begin{array}{lllllll}0 & 20 & 40 & 60 & 80 & 100 & 120\end{array}$

Fig. 3 Moisture trajectories and water vapor transport for three selected flood events. The mechanism of Tropical Moisture Exports (TMEs) (source, track, and specific humidity variation) associated with a long (i: May 1999), moderate (ii: September 2008), and short (iii: October 1980) duration flood event that occurred in the Missouri River Basin a. The color indicates the change of specific humidity $\Delta \mathrm{Q}$ [g kg ${ }^{-1}$ ]. A $37-\mathrm{day}$ time-lapse of Integrated Vapor Transport [IVT] for each of the indicated flood durations is also presented b. Thick hollow boxes show an organized (and significant) system of water vapor transport from the ocean towards the land

wave atmospheric circulation system. This moisture transport phenomenon coincided with a similar Omega blocking structure given in Fig. 1a (i), causing multiple days of moisture convergence and release, as the warm moist air parcels were forced to condense. The process of such condensation assisted the dissipation of the energy of the Omega blocking system. A similarly strong association between moisture transport, convergence, and release were observed for the MRB in recent studies. $^{12,39}$ That preliminary exploratory analysis between the floods, the antecedent wet condition, and moisture transport mechanisms $^{12}$ has led to the comprehensive diagnostics and modeling study presented in this paper.

Inference of flood duration using cumulative flow exceedance and atmospheric dynamics

Based on the indicated diagnostics above, we developed a physically informed Bayesian inference model that quantifies the interactions in a hierarchical network framework. Figure 5a shows the joint mapping of flood duration with the divergence of wind
(divW), geopotential height dipole index (GPH-di), CEl, and available moisture in the air column as indicated by the vertically integrated water vapor (viWV) over the MRB. Readers are referred to the Methods for the derivation of these indices. The horizontal and vertical axes correspond to the divW and GPH-di for the flood events. The viWV is indicated by the size of the circle. The color spectrum of the circles represents the minimum, $25^{\text {th }}, 50^{\text {th }}, 75^{\text {th }}$, $97.5^{\text {th }}$, and the $99^{\text {th }}$ percentiles of the distribution of CEI-orange to red for the filled river conditions (excessive flow accumulation) and sky blue to blue-gray for the empty (dry) river conditions. The number presented in the circle denotes the duration of the flood in days. A total of 30 events (1979-2014) are presented in this figure (the 6 years with no floods are not presented here). Among these, nine are long-duration floods ( $\geq 21$ days), 13 are moderate (7-21 days), and eight are short (less than 7 days) duration floods.

The first quadrant (top-right) indicates more than the average divergence of the wind and positive GPH-di. As discussed in the previous section, a high divergence of wind (large negative VP anomalies) represents deep convection and pre-conditions for sustained precipitation. Similarly, a positive GPH-di suggests an 


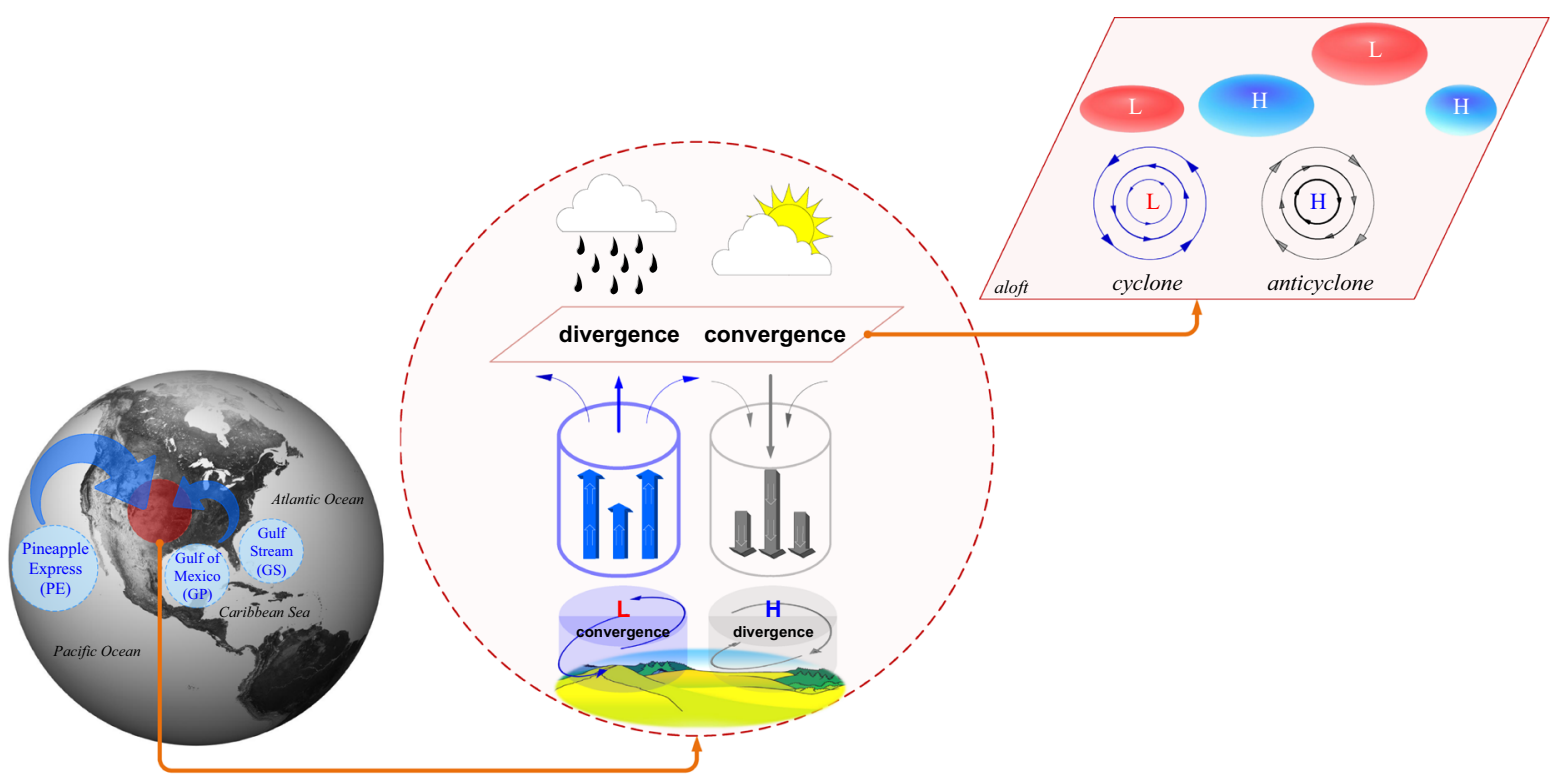

b
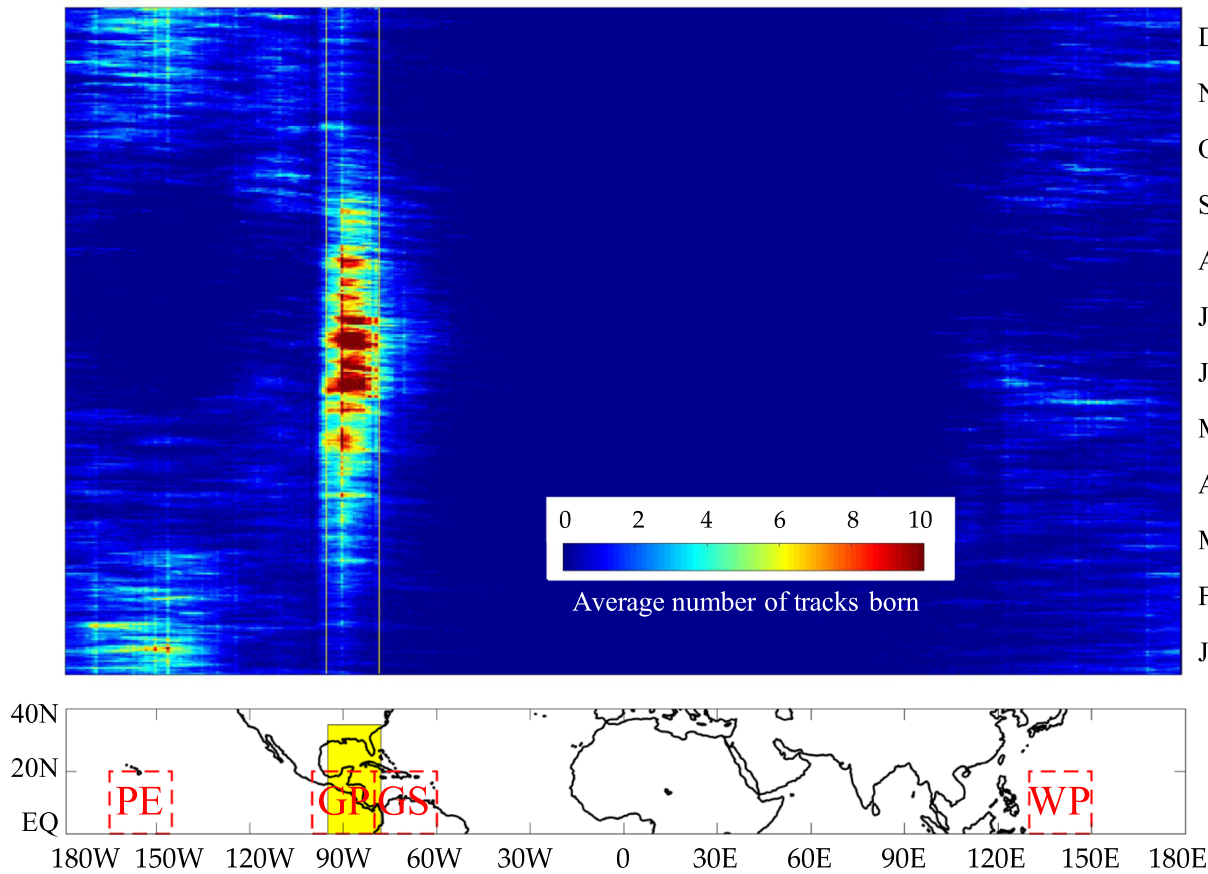

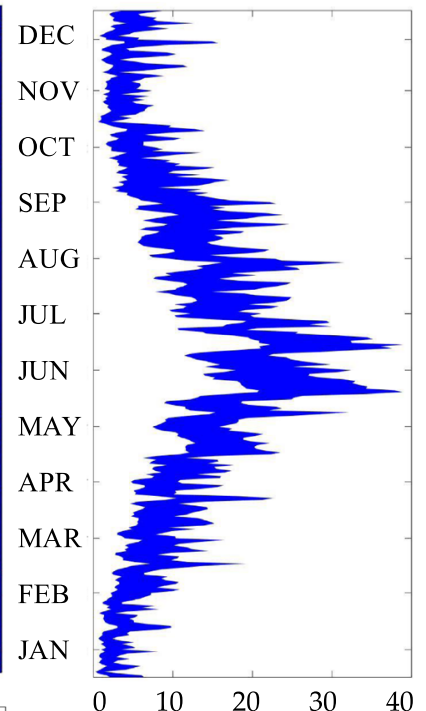

Number of tracks born

Fig. 4 Large-scale system of divergent wind, regional pressure blocking and spatiotemporal distribution of moisture trajectories. A schematic of oceanic sources of moisture and system of divergence/convergence patterns (from both vertical and horizontal perspectives) in the presence of atmospheric blocking and cyclonic/anticyclonic pressure columns a. Space-time configuration of Tropical Moisture Exports (TMEs) for the flood events (source, number of tracks, and seasonality) b. The four main TME sources are Pineapple Express (PE), Great Plain (GP) (i.e., from Gulf of Mexico), Gulf Stream (GS), and West Pacific (WP) at the global scale. The Gulf of Mexico is highlighted in yellow as the major source of TMEs for the floods in the Missouri River Basin

atmospheric blocking phenomenon. Among the nine longduration floods, five are associated with high divergence of the wind with positive GPH-di. The pre-conditioning of sustained convective events along with enough water vapor in the atmosphere led to a high preceding flow condition, as seen in the color of the circles, causing floods that last long. Five out of the eight short-duration floods have a less than average divergence of the wind $\left(<1 \times 10^{-5}\left[\mathrm{~s}^{-1}\right]\right)$. Moreover, they are also associated with a very low preceding flow accumulation (CEI $<3$ [cfs $\mathrm{Cfs}^{-1}$ ]). Some of these events, as seen in the third quadrant, also have a negative GPH-di implying a weak atmospheric blocking phenomenon. It is hence evident that floods occurring during these land and atmospheric conditions will have a short peak and fast recession. We point the readers to two rounded rectangular (I and II) in Fig. 5a, which highlight the intricacies of these land-atmosphere interactions. We see two events in rounded rectangle (I) with very similar atmospheric features, i.e., they have the same divergence of wind and blocking phenomena; however, one event with low preceding flow accumulation leads to an 8-day flood, while the other with high preceding flow 

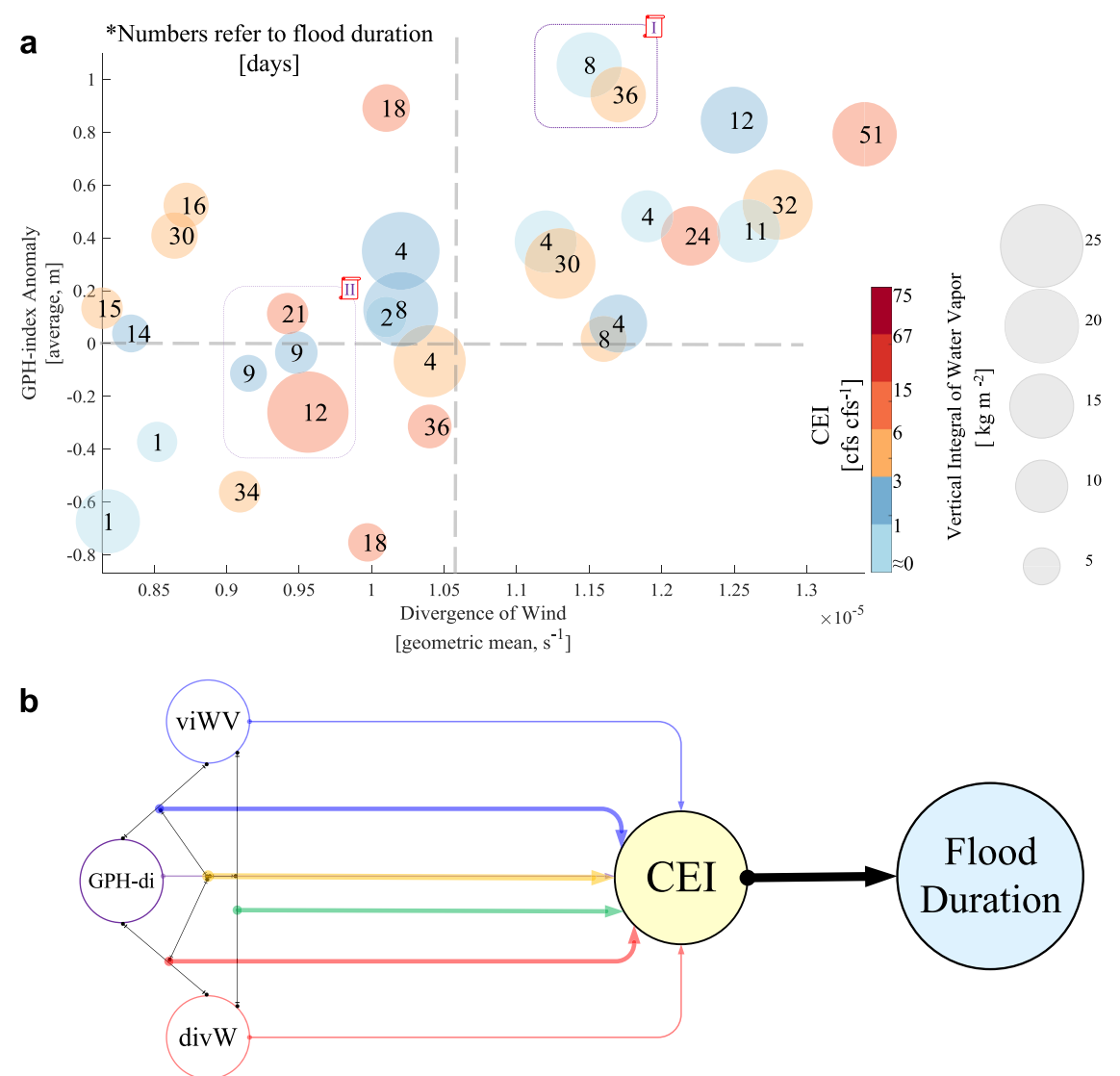

Fig. 5 An integrated view of available moist air, atmospheric circulation and pressure blocking system that determines surface preceding flow accumulation and flood duration under individual contributions or multiple combined configurations of atmospheric drivers. A long flood duration ( $\mathrm{Fd}$ ) event is proportional to large divergence of wind (divW), large positive pressure dipole (GPH-di), and existence of higher cumulative exceeding flow (CEI) a. Two specific examples are annotated by rounded rectangulars (I) and (II) and their land-atmosphere interactions and their multivariate intercorrelations are discussed in the text. All potential univariate and multivariate combinations of the mesoscale variables that regulate $\mathrm{CEl}$ are also presented $\mathbf{b}$

accumulations leads to a 36-day flood (a long-duration one). A similar pattern can be seen in the rounded rectangular (II) in Fig. 5a. There are four events in rounded rectangular (II); 21, 9, 9, and 12 days of flood durations. Although the 21-day flood has a preceding flow accumulation and divergent wind in the same range as the 12-day flood, even with much less water vapor in the atmosphere $\left(6.6 \mathrm{~kg} \mathrm{~m}^{-2}\right)$, the positive blocking feature (GPH-di $=$ +0.11 ) could compensate the shortage of available water vapor in the pressure column through stagnation of the atmospheric state and enhancing the downpours, which will ultimately lead to a longer flood.

Considering such complexity and multivariate dependencies between the preceding flow regime and the atmospheric components, we explore the idea of identifying these individual and joint connections through an inference model. In Fig. 5b we indicate all different individual connections and connections resulting from various combinations of the atmospheric variables that can determine CEI and ultimately the duration of the flood. We set this up in a hypothesis framework where the variables are interacting at different hierarchical levels; CEI informing flood as a model that represents the land surface interactions, and the atmospheric variables (independent and interactive) informing the preceding flow regime (CEI) as a model of the atmospheric coupling. To uncover deeper connections in the atmospheric system, we explore all combinations including the two-way and the three-way interaction terms. These are shown in thicker connectors in the figure. For instance, the combined contribution of GPH-di $\times$ viWV (blue thick arrow in Fig. 5b) in addition to the contribution of GPH-di and viWV exclusively (thin purple and thin arrows) can trigger a specific CEl and then Fd.

We developed a two-level Bayesian network model as a physically based inference engine for flood duration to quantify these interactions. The best model combination in terms of the lowest deviance information criteria (DIC), a measure of the model's posterior predictive skill, from a step-wise model search is shown in Fig. 6a. A list of other model combinations and their DIC is given in Supplementary Table 1. The first layer (regional flood duration scaling of the form $\mathbf{F d} \sim \mathbf{C E I}^{\boldsymbol{\beta}}$ ) estimates the variability of flood duration using CEI (i.e., the influence of antecedent flow accumulations-beyond a threshold-on Fd) for each of the five major reservoirs in the MRB (i.e., Smithville, Cottonwood Creek, Oahe, Lake Babcock-North Columbus, and Fort Peck). The second layer, in turn, estimates CEl conditional on the interaction of GPHdi with a synergistic model containing viWV and divW, and their interactions for all the indicated reservoirs. This way, the model jointly captures the hydrologic scaling and the dynamic atmospheric scaling. It is interesting to note that the best model combination, when re-expressed using factorization, reveals how atmospheric blocking phenomena (GPH-di) dynamically couples with regional vertical interactions. This dynamic atmospheric scaling is expressed as CEI $\sim \exp \left(\mathbf{G P H}-\mathbf{d i} \times\left(\boldsymbol{\gamma}_{\mathbf{1}}+\mathbf{Y}_{\mathbf{2}} \mathbf{v i W V}+\right.\right.$ $\left.\mathbf{Y}_{\mathbf{3}} \operatorname{div} \mathbf{W}+\mathbf{Y}_{\mathbf{4}} \mathbf{v i W V} \times \mathbf{d i v} \mathbf{W}\right)$ ), where exp is the exponential function. It shows how the atmospheric variables in the vertical column are interacting with the blocking feature to set up the necessary and sufficient conditions for a high preceding flow regime, which in turn will cause a large flood. Readers are referred to the Methods 

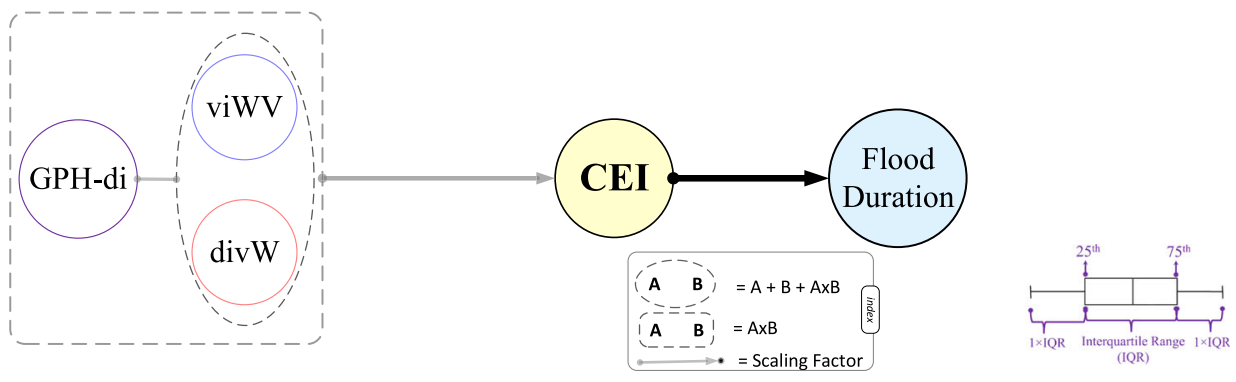

b
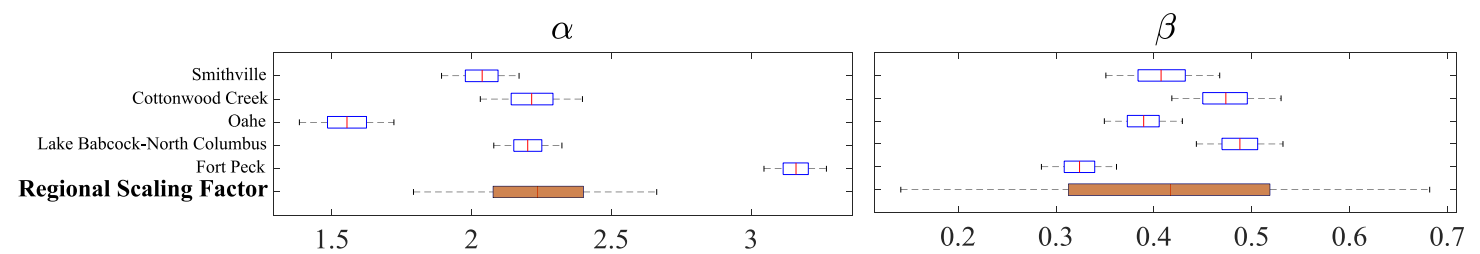

C
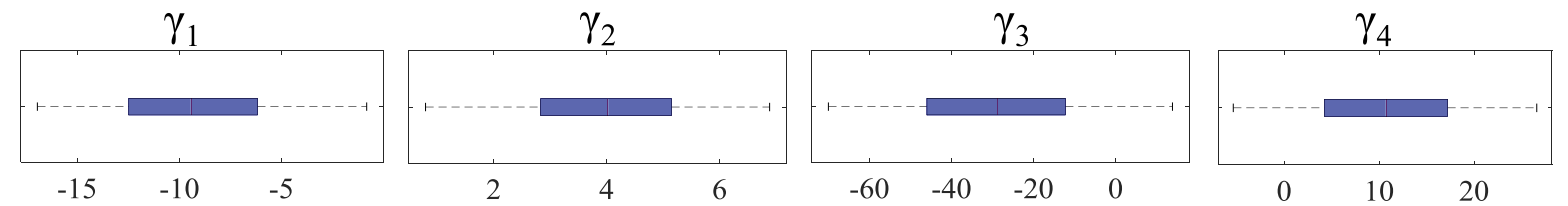

Long duration

d reservoir (dam)

Smithville

Cottonwood Creek

Oahe

Lake Babcock-North Columbus

Fort Peck

1979 Yea

1985

1990

1995

2000

2005

2010

Probability

$\begin{array}{lllllllll}0.1 & 0.2 & 0.3 & 0.4 & 0.5 & 0.6 & 0.7 & 0.8 & 0.9\end{array}$

e reservoir (dam)

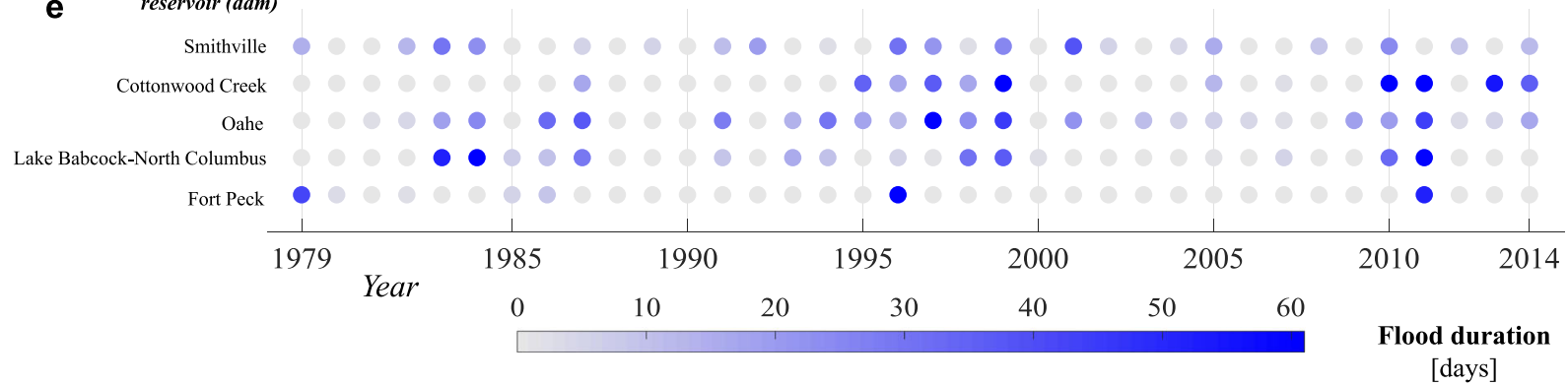

Fig. 6 A two-layer network model for Bayesian inference of the coupled regional flood duration scaling and atmospheric dynamic scaling of the flood duration. GPH-dipole index (GPH-di) is interacting with the synergistic model of vertical integral of water vapor (viWV) and the divergence of the wind (divW) to control the cumulative exceeding flow index (CEI) in the second level (dynamic atmospheric scaling), and ultimately the flood duration in the first level (regional flood duration scaling) a. Posterior distribution of the estimated $\alpha$ (intercept) and $\beta$ (slope) for each reservoir in the regional flood duration model and their regionally averaged scaling factor (medians and $80 \%$ intervals) b, the posterior distribution of the estimated $\gamma_{1}, \gamma_{2}, \gamma_{3}$, and $\gamma_{4}$ for $(\mathrm{GPH}-\mathrm{di})$, (GPH-di $\times$ viWV), (GPH-di $\left.\times \operatorname{divW}\right),(\mathrm{GPH}-\mathrm{di} \times \mathrm{viWV} \times \operatorname{divW})$ as the atmospheric scaling factors in the atmospheric dynamic model c. The probability that a flood will be a long-duration one (i.e., 21 days and above) for each reservoir in a given year derived from the two-layer network model of coupling regional flood duration and dynamic atmospheric scaling d compared with the observed flood durations based on the records from 1979 to 2014 e

section for the details of the model. The boxplots of the posterior distributions of the regression intercept and slope parameters from the regional flood duration scaling model ( $\boldsymbol{\alpha}$ and $\boldsymbol{\beta}$, and their regional average scaling factor) and the dynamic atmospheric scaling model $\left(\boldsymbol{\gamma}_{\mathbf{1}}, \mathbf{\gamma}_{\mathbf{2}}, \mathbf{Y}_{\mathbf{3}}\right.$, and $\left.\mathbf{\gamma}_{\mathbf{4}}\right)$ are presented in Fig. $6 \mathrm{~b}, \mathrm{c}$, respectively. The hydrologic scaling factors that connect CEI with the duration of the flood (in the log plane) range between 0.32 and 0.49 with a median regional hydrologic scaling factor of 0.42 . The atmospheric scaling factors for GPH-di $\left(\gamma_{1}\right)$, GPH-di $\times \operatorname{viWV}\left(\gamma_{2}\right)$, GPH-di $\times \operatorname{divW}\left(\gamma_{3}\right), G P H-d i \times \operatorname{viWV} \times \operatorname{divW}\left(\gamma_{4}\right)$ have switching positive and negative signs owing to some level of common information. The estimated coefficients $\gamma_{1}, \gamma_{2}, \gamma_{3}$, and $\gamma_{4}$ are -9.17 
(with a standard error of 6.2), 3.9 (standard error $=2.3$ ), -28.6 (standard error $=31.4$ ), and 10.67 (standard error $=12.1$ ), respectively.

Given the posterior distribution of the predicted flood duration, one can estimate, for each year, the probability that the flood duration will be greater than or equal to 21 days (the threshold for long-duration flood). Figure $6 \mathrm{~d}$ shows these probability estimates as colored circles for each year and reservoir from 1979 to 2014. The measured flood durations based on the historical data are given in Fig. 6e, indicated by a white to dark-colored spectrum for longer flood durations. In any given year, a high forecast probability provides a strong directional indication of a longduration flood. We can see from the results that the model predicted high probabilities for all the years and individual reservoirs when the flood was of long duration. We also see such similar accurate predictions with a high success rate for all the years and individual reservoirs with short and moderate-duration floods. The probabilistic predictions for short and moderateduration floods are provided in Supplementary Fig. 6. The boxplots related to the posterior probability distribution of $\mathrm{Fd}$ and CEI for the five reservoirs are shown in Supplementary Fig. 7 with their actual observations. We can see that the directional indicator of the predictions is generally accurate; as the uncertainty varies from year to year.

These predictions of the preceding flow accumulations, and on whether a long (or moderate and short) duration flood will occur or not could potentially be used to transform the current flood control practices into ones that use dynamically updated information from the ocean, atmosphere, and land conditions. They provide a practical scheme of how one could utilize the flood duration prediction based on the land and atmosphere predictors to design a more realistic integrated flood risk management and vulnerability assessment. Accurately determining the duration of the floods, in particular, the long-duration floods is vital to project the socioeconomic exposures to the flood inundation. From an operational standpoint, reservoir managers can prescribe their action thresholds based on the flood duration and evaluate the probability of floods and their consequences relative to these thresholds and the uncertainty in the predictions. ${ }^{41}$

From diagnostic understanding to proactive decision support towards stronger resilience against natural hazards

We have shown in this investigation that long-lasting floods can be related to persistent variables in the hierarchy of the climate and atmospheric system. Long-duration floods are triggered by high antecedent flow conditions, which are in turn caused by high moisture release from the recurrent storm tracks. Atmospheric teleconnections are distinctively persistent and well developed for these events. For short-duration floods, these coupled patterns are insignificant. A Bayesian network inference model has been developed to quantify these relations and for predicting the likelihood of floods of varying duration using physics informed predictors. We have also introduced an integrated regional flood duration scaling and atmospheric dynamic scaling framework that together enable the coupling of 'horizontal' and 'vertical' flow of information (e.g., accumulation of streamflow in the basin in the presence of the interrelated land-atmosphere interactions and rainfall episodes) across different space and time scales. An improved understanding of the critical forcing of hydrologic systems by meteorological and climatic processes is an essential aspect to factor-in when predicting their functioning and building decision support frameworks to build resilience against natural hazards, especially as adaptive measures are being considered for the future extreme events. The analyses of their causal structure will be invaluable for evaluating reservoir and river system operation policies, flood preparation and hence on the economy and security of the country as critical issues are addressed in this direction.

\section{METHODS}

Flood duration, initial flow fraction, and cumulative exceeding flow

Flood duration and the initial flow fraction data from 1966 to 2014 (49 years) for the five major reservoirs in the MRB (i.e., Smithville, Cottonwood Creek, Oahe, Lake Babcock-North Columbus, and Fort Peck) are used for this study. The data were obtained from our previous comprehensive study of the flood characteristics in large reservoirs of the MRB. ${ }^{12}$ Annual flood duration is defined as the total number of days (within a window of 30 days around the annual maximum flood peak as employed in ${ }^{12}$ ) when the daily streamflow $\left(\mathrm{Q}_{\mathrm{i}}\right)$ exceeds a chosen threshold $\left(\mathrm{Q}^{*}\right)$. We used the ninetieth percentile of the daily flows as the threshold, which, in this basin, corresponds to an average return period of 1.15 years. ${ }^{12}$ Flood duration (Fd) for each selected streamflow station-co-located with a large reservoir in the MRB-is measured using the following duration formula: ${ }^{12}$

$F d=\sum_{i=T-30}^{T+30} d_{i}$ where $d_{i}=\left\{\begin{array}{c}1 \text { if } Q_{i} \geq Q^{*} \\ 0 \text { if } Q_{i}<Q^{*}\end{array}\right.$

Each year, the median flood duration across the five reservoirs in the MRB is considered for the analysis (Supplementary Fig. 1). Their occurrence dates $(T)$ are also recorded. There are 9,20 , and 20 flood events in the long ( 21 days and above), moderate (between 7 and 21 days) and short (less than or equal to 7 days) duration flood categories, respectively. These durational categories are consistent with the global active archive of flood events and their statistics, provided by the Dartmouth Flood Observatory (DFO). ${ }^{3,32}$

We estimated the initial flow fractions as the ratio of the daily discharge to Q* (ninetieth percentile of entire daily streamflow for that reservoir) for up to 37 days $(7+30$ days) preceding the flood peak.

$Q f_{i}=\frac{Q_{i}}{Q^{*}}$

where $i$ refers to a time-increment starting from $T-37$ to the time of the flood peak, $T$.

Using $\mathrm{Qf}_{\mathrm{i}}$, we calculate the maximum cumulative exceeding flow for the 37-day period, i.e., CEI as follows:

$$
\begin{gathered}
\text { excess }_{i}=\max \left\{\text { excess }_{i-1}+\mathrm{Qf}_{\mathrm{i}}-1,0\right\} ; \text { excess }_{i=0}=0 \\
\mathrm{CEI}=\max _{(i=T-37 \text { to } T)}\{\text { excess }\}
\end{gathered}
$$

where excess is a vector of cumulative exceeding Qf values 37 days preceding the flood peak, excess $s_{i}$ is the daily cumulative exceeding flow that indicates the normalized flow exceedance above $Q f=1$ (a bankfull discharge state) over a period of 37 days (i.e., $i=\mathrm{T}-37$ to $\mathrm{T}$ ). The maximum over these 37 days is defined as the cumulative exceedance index (CEI). Since excess $s_{i}$ is referenced to $Q f=1$, persistent flow exceeding the flood threshold $\left(Q_{i}>Q^{*}\right)$ indicates the accumulated flow beyond this threshold. The magnitude of this accumulation is reduced when the flow is below the threshold $\left(Q_{i}<Q^{*}\right)$. Hence, if the flow is continuously above the flood threshold, excess $s_{i}$ increases monotonically. If the flow is constantly below the flood threshold, excess $s_{i}$ is 0 . The maximum of this accumulation (i.e., CEI) is the peak of this function that can serve as a proxy for the evolving flood condition in the basin.

We choose a window of 30 days in determining the flood duration to provide a large enough window to capture the flood accent and recession periods around the peak flow and any multiple events before or after the peak in each year. All the flood events have a total duration of less than 60 days indicating that duration index is not sensitive to the size of the window. Further, we find that $56 \%$ of the flood duration on average typically happens after the flood peak, indicating the slow recession nature of long-duration floods. Hence, we can accumulate the (multiple) flood(s) caused by recurrent rainfall events and saturated soil conditions within a robust temporal coverage. In addition, the choice of 7 days preceding of flood duration window is contextualized as the maximum required travel time (i.e., 7-day evolution time) for the storm tracks from the tropics towards higher latitudes. This ultimately can be projected on the $\mathrm{Qf}_{\mathrm{i}}$ and CEI with a 7-day margin. 
Tropical moisture exports and storm tracks

The Tropical Moisture Exports (TMEs) dataset is used in this study to identify the contributing atmospheric moisture born in the tropical warmer oceanic areas and diagnose the associated atmospheric steering mechanism. The TMEs were first documented in ref. ${ }^{36}$ for the northern hemisphere and later extended to a global climatology covering $1979-2013 .^{42}$ The TMEs are daily tropical $\left[20^{\circ} \mathrm{S}-20^{\circ} \mathrm{N}\right]$ born moisture tracks calculated using 6-hourly ERA-Interim data ${ }^{43}$ with the LAGRANTO Lagrangian analysis tool. ${ }^{44}$ All TMEs' tracks are recorded up to 7 days (29 points of positions in total) and must reach $35^{\circ} \mathrm{N}$ within the next 5-6 days after crossing $20^{\circ} \mathrm{N}$ with a minimum water vapor fluxes of $100\left[\mathrm{~g} \mathrm{~kg}^{-1} \mathrm{~m} \mathrm{~s}^{-1}\right]$. It was shown in $^{36,45}$ that TMEs contribute significantly to climatological precipitation especially in the mid-latitudes. Our previous studies ${ }^{12,18,40}$ exhibited the strong links between TMEs and floods in the extratropical regions, including Western Europe, Northeastern United States, and the MRB. ${ }^{18}$ developed a predictive model for flood-triggering daily precipitation using extracted atmospheric circulation patterns associated with such moisture transport. There are four identified major TMEs moisture sources as hotspots in the tropical region $\left[20^{\circ} \mathrm{S}-20^{\circ} \mathrm{N}\right]:^{36}$ (1) 'Pineapple Express' (PE) $\left[170^{\circ}-130^{\circ} \mathrm{W}\right]$; (2) 'Great Plain' (GP) $\left[100^{\circ}-90^{\circ} \mathrm{W}\right]$; (3) 'Gulf Stream' (GS) $\left[40^{\circ}-70^{\circ} \mathrm{W}\right]$; and (4) 'West Pacific' (WP) $\left[120^{\circ}-170^{\circ} \mathrm{E}\right]$. These four regions are illustrated in Fig. $4 \mathrm{~b}$. Their climatological contribution to the MRB is also shown. The following two procedures were conducted next:

(1) Space-time moisture source climatology analysis for the MRB: The climatological contribution of TMEs to the MRB is examined based on a calendar day climatological analysis of the TMEs that have entered the MRB during their lifetime (7 days after their birth in the tropics). The results are illustrated in Fig. 4b. Top-left panel is showing the calendar day climatology of TMEs born in different longitude (horizontal axis), the calculation is a daily average of TMEs born at different longitude that entered the MRB; bottom-left panel shows the matching global longitudinal band $\left[0-40^{\circ} \mathrm{N}\right]$ with four major TMEs source hotspots marked (i.e., PE, GP, GS, and WP). The plot on the right shows the interannual variability of the main moisture source (the Gulf of Mexico, mainly the GP hotspot region, marked in yellow) during summer season, with the areas covering two standard deviations away from the calendar day average over the regions between the yellow lines in the top-left plot or the yellow shaded area at the bottom right.

(2) Diagnosis of moisture transports for exemplified flood events with different durations: Three flood events (out of three long, moderate, and short-duration flood scenarios) in the MRB (Fig. 3a) were selected to explore the association between antecedent moisture transport and the occurrence and duration of floods. These include a long-duration flood in May 1999 (Fig. 3a (i)), a medium-duration flood in September 2008 (Fig. 3a (ii)) and a short-duration flood in October 1980 (Fig. 3a (iii)). We use TMEs dataset to filter all tracks that entering the $\mathrm{MRB}$ region $\left[35^{\circ} \mathrm{N}-50^{\circ} \mathrm{N}, 115^{\circ} \mathrm{W}-90^{\circ} \mathrm{W}\right]$, from 37 days to 7 days before the flood peak (this time window is also consistent with the definition of Qf). The idea is to link the moisture transport directly to the antecedent wetness condition, i.e., Qf. In addition, the change of moisture (recharge or release) along each track is calculated as below:

$\Delta Q_{k}(j)=Q_{k}(j)-Q_{k}(j+1)$

where $j$ is the time point on the track (the $j^{\text {th }}$ position along the track), $Q_{k}(j)$ is the $k^{\text {th }}$ TMEs track's specific humidity $\left[\mathrm{g} \mathrm{kg}^{-1}\right.$ ] at the time point $j$ and $\Delta Q_{k}(j)$ is the change of specific humidity. Each track has its position(s) recorded every $6 \mathrm{~h}$, up to 7 days, with a total of 29 points. Thus, $j$ ranges from 0 to 28 , with the birth location recorded at $j=0$ and the position before death recorded at $j=28$. Note that we consider the tracks leaving/ exiting at the different hours of the day, i.e., 0, 6, 12, 18, and 24 o'clock, and only those entered MRB during their lifetime are shown in Fig. 3a (we provided more trajectories in Supplementary Fig. 3). By examining the selected tracks and their release of moisture to the study area, the antecedent condition and amounts of moisture transport (if any) associated with moisture birth location and their trajectories to the MRB can be identified.

\section{Large-scale atmospheric data}

Daily composite of Geopotential Height (GPH) anomalies at $500 \mathrm{mb}$ level and Velocity Potential (VP) anomalies at 0.2582 sigma level are obtained from the NCEP/NCAR reanalysis database. ${ }^{46}$ The data is available at $2.5^{\circ} \times$ $2.5^{\circ}$ spatial resolution. We developed a GPH-dipole index (GPH-di) using two adjacent hotspots (Supplementary Fig. 4) corresponding to positive GPH values (i.e., L: low-pressure column) -spatially averaged over $57.0-62.0^{\circ} \mathrm{N}$ and $95.0-100.0^{\circ} \mathrm{W}-$ and negative GPH values (i.e., $\mathrm{H}$ : highpressure column) - spatially averaged over $40.0-45.0^{\circ} \mathrm{N}$ and $105.0-110.0^{\circ} \mathrm{W}$. These hotspots have significant low/high GPH anomalies at the time of flood events in the MRB. ${ }^{12}$ Thus GPH-di is calculated as:

$\mathrm{GPH}-\mathrm{di}=\mathrm{L}-\mathrm{H}=$ Low-pressure column - High-pressure column

It should be highlighted here that the large positive GPH-di values correspond to the formation of an effective blocking system of atmospheric pressure aloft which can gently hold the entering moisture into the basin.

The $0.125^{\circ} \times 0.125^{\circ}$ gridded atmospheric data of the vertical integral of Water Vapor (viWV) and divergence of Wind (divW) at $500 \mathrm{mb}$ pressure level were also processed from ECMWF ERA-Interim daily reanalysis project. ${ }^{43}$ They were spatially averaged over a rectangular grid box of $35.0-50.0^{\circ} \mathrm{N}$ and $90.0-115.0^{\circ} \mathrm{W}$ above the MRB from January 1,1979 , to December 31, 2014. Their geometric means were calculated from 37 through 7 days preceding each flood event. We applied the geometric mean to quantify the central tendency of the viWV and divW (i.e., directional increase or decrease behavior) as it approaches the flood peak (flood timing). The covariation of GPH-di, viWV, and divW, with respect to CEI is given in Supplementary Fig. 5.

\section{Integrated moisture flux convergence and advection}

The vertically integrated water vapor transport (IVT) is a metric used to quantify the poleward structure of extratropical atmospheric water vapor flux (e.g.. $\left.{ }^{20,47}\right)$. Large-scale advection of water vapor into a specific region (moisture convergence) by winds can enhance heavy precipitation events due to constantly transporting moisture toward that region. The enhanced moisture advection mostly occurs as the mid-latitude cyclones carry an organized corridor of moisture-through ARs-from the subtropics towards extratropics and higher latitudes. ${ }^{48}$ The horizontal transport of total column atmospheric water vapor $\left(\mathrm{kg} \mathrm{m}^{-2}\right)$ forced by the zonal and meridional winds (i.e., $\mathrm{u}$ and $\mathrm{v} ; \mathrm{m} \mathrm{s}^{-1}$ ) between two vertical pressure levels $(1000$ and $300 \mathrm{hPa})$ is defined as follows:

$I V T=\frac{1}{g} \int_{1000}^{300} q \cdot V d p=\frac{1}{g} \sqrt{\left(\int_{1000}^{300} q \cdot u d p\right)^{2}+\left(\int_{1000}^{300} q \cdot v d p\right)^{2}}$

where $q$ is the specific humidity $\left(\mathrm{kg} \mathrm{kg}^{-1}\right), V$ is the wind vector $\left(\mathrm{m} \mathrm{s}^{-1}\right), d p$ refers to the pressure difference between two adjacent vertical levels, and $\mathrm{g}$ indicates the acceleration induced by gravity $\left(9.81 \mathrm{~m} \mathrm{~s}^{-2}\right)$. The daily IVT values $\left(\mathrm{kg} \mathrm{m}^{-1} \mathrm{~s}^{-1}\right)$ at the global scale are calculated from the NCEP/NCAR reanalysis 1 database $e^{46}$ at $2.5^{\circ} \times 2.5^{\circ}$ spatial resolution for the period 1966-2014 (49 years).

\section{Integrated regional flood duration and dynamic atmospheric scaling}

Floods of varying duration can be associated with the antecedent flow conditions and precedent synoptic circulation patterns at various levels of the hierarchy in the climate system. Slowly varying ocean-atmospheric processes can be translated into significant and persistent changes in the probability of major events in the large river basins. Mapping these factors into a statistical-dynamical inference (prediction) framework is necessary for establishing a process by which long-duration flood risk can be systematically updated that reflects the changing conditions. Hierarchical Bayesian network models provide a systematic way to model such connected systems with uncertainty propagation across multiple hierarchical layers that are typical in coupled land-atmosphere systems. ${ }^{49}$ In addition to the diagnostic analysis presented in this study, we also developed a new Bayesian network based inference model to integrate the regional and atmospheric layers based on the preceding flow accumulations, which in turn are predicted based on the synoptic circulation indices and their dynamical interactions. We factorize the coupled system into hydrologic scaling and dynamic atmospheric scaling models. In the regional flood duration model (level 1), the maximum antecedent exceeding flow accumulation (CEI) informs the flood duration. In the atmospheric model (level 2), the maximum antecedent exceeding flow accumulations are informed by; (1) GPH-di, (2) product of the GPH-di and viWV, i.e., when viWV interacts with the atmospheric system of blocking pressure, (3) product of GPH-di and divW, i.e., the interaction of winds with the atmospheric system of blocking pressure, and (4) product of GPH-di 
and viWV and divW, i.e., when the winds and water vapor and system of blocking pressure are interacting at the same time. This two-layer system recognizes that the information of the atmospheric predictors is already contained in the preceding flow conditions, hence mapping the hierarchical climate system to the flow predictions. Thus, we developed an integrated multilevel model of the following form:

Layer 1) Regional flood duration scaling:

$F d_{r} \sim \operatorname{Poisson}\left(\lambda_{r}\right)$

$\operatorname{Ln}\left(\lambda_{r}\right)=a_{r}+\beta_{r} \operatorname{Ln}(C E I)$

$\left[\begin{array}{c}a_{r} \\ \beta_{r}\end{array}\right] \sim \operatorname{MVN}\left(\begin{array}{l}\mu_{a} \\ \mu_{\beta}, \sum_{a, \beta}\end{array}\right)$

Layer 2) Atmospheric dynamic scaling:

$$
\begin{aligned}
& \operatorname{Ln}(\mathrm{CEI}) \sim \operatorname{Normal}\left(\mu_{\mathrm{CEI}}, \sigma_{\mathrm{CEI}}^{2}\right) \\
& \mu_{\mathrm{CEI}}=\delta+\gamma_{1}(\mathrm{GPH}-\mathrm{di}) \\
&+\gamma_{2}(\mathrm{GPH}-\mathrm{di}) \cdot \operatorname{Ln}(\mathrm{viWV}) \\
&+\gamma_{3}(\mathrm{GPH}-\mathrm{di}) \cdot \operatorname{Ln}(\mathrm{divW}) \\
&+\gamma_{4}(\mathrm{GPH}-\mathrm{di}) \cdot \operatorname{Ln}(\mathrm{viWV}) \cdot \operatorname{Ln}(\operatorname{divW})
\end{aligned}
$$

The first level of model considers a Poisson distribution with a timevarying rate parameter $(\lambda)$ for the duration of floods. $\lambda$, the rate parameter is informed by a regression on the antecedent exceeding flow accumulations with intercept $a$ and coefficient $\beta$ for each reservoir $r$. The second level of the model considers that the CEl used as the predictor in the first level can be estimated using the preceding synoptic circulation predictors; i.e., $G P H-d i$, the product of the $G P H-d i$ and viWV to effectively address the interaction of water vapor with the atmospheric blocking pressure, and the product of GPH-di and divW for interaction of the divergence of wind with atmospheric blocking pressure. This multilevel structure allows a systematic accounting/propagation of parameter uncertainties in both models. The covariance $\Sigma_{a, \beta}$ and variance $\sigma^{2}{ }_{C E I}$ represent error variances in both the models, i.e., variation beyond what can be explained by the chosen predictors.

The joint posterior distribution $\mathrm{P}(\Theta \mid$ data $)$ of the parameter vector is derived by combining the prior distributions and the likelihood functions. We assumed a uniform prior distribution for the variance terms and uninformative normal priors for the coefficients. ${ }^{49}$ The parameters are estimated using JAGS (Just Another Gibbs Sampler) ${ }^{50}$ which employs the Gibbs sampler, a Markov Chain Monte Carlo (MCMC) method for simulating the posterior probability distribution of the parameters conditional on the current choice of parameters and the data. Three consecutive chains are simulated using the random initial values for the parameters. Each chain was run for 30,000 cycles with $95 \%$ burn-in to discard the initial estimations. We monitor the convergence using a shrink factor. ${ }^{49}$ The ratio of variance between chains and variance within chains should be lower than 1.1.

It should be noted that the formulation for the regional flood duration scaling and dynamic atmospheric scaling can be re-expressed as scaling functions as follows:

$$
\begin{aligned}
F d & =\vartheta \mathrm{CEI}^{\beta} \xi \rightarrow \\
\operatorname{Ln}(F d) & =\underbrace{\operatorname{Ln}(\vartheta)}_{a}+\beta \operatorname{Ln}(\mathrm{CEI})+\underbrace{\operatorname{Ln}(\xi)}_{\text {error }} \\
& \Rightarrow \operatorname{Ln}(F d)=a+\beta \operatorname{Ln}(\mathrm{CEI})
\end{aligned}
$$

And similarly,

$$
\begin{aligned}
& C E I=\eta \cdot \psi \cdot e_{\text {Part }}^{(\mathrm{GPH}-\mathrm{di})} \cdot \underbrace{\left(\gamma_{1}+\gamma_{2} \operatorname{Ln}(v i W V)+\gamma_{3} \operatorname{Ln}(\operatorname{div} W)+\gamma_{4} \operatorname{Ln}(v i W V) \cdot \operatorname{Ln}(\operatorname{div} W)\right)}_{\text {PattI }} \rightarrow \\
& \operatorname{Ln}(C E I)=\underbrace{\operatorname{Ln}(\eta)}_{\delta}+\underbrace{\operatorname{Ln}(\psi)}_{\text {error }}+ \\
& (\mathrm{GPH}-\mathrm{di}) \cdot\left(\gamma_{1}+\gamma_{2} \operatorname{Ln}(v i W V)+\gamma_{3} \operatorname{Ln}(\operatorname{div} W)+\gamma_{4} \operatorname{Ln}(v i W V) \cdot \operatorname{Ln}(\operatorname{div} W)\right) \\
& \rightarrow \operatorname{Ln}(C E I)=\delta+\gamma_{1}(\mathrm{GPH}-\mathrm{di})+ \\
& \gamma_{2}(\mathrm{GPH}-\mathrm{di}) \cdot \operatorname{Ln}(\mathrm{viWV}) \\
& \gamma_{3}(\mathrm{GPH}-\mathrm{di}) \cdot \operatorname{Ln}(\operatorname{divW})+ \\
& \gamma_{4}(\mathrm{GPH}-\mathrm{di}) \cdot \operatorname{Ln}(\operatorname{viWV}) \cdot \operatorname{Ln}(\operatorname{divW})
\end{aligned}
$$

where $\alpha$ and $\beta$ are the scaling coefficients in the first level for the regional flood duration model, and $\gamma_{1}, \gamma_{2}, \gamma_{3}$, and $\gamma_{4}$ are the scaling coefficients in the second level related to the atmospheric dynamic model.

\section{DATA AVAILABILITY}

The data needed to evaluate the conclusions in the paper are present in the present paper, our previous published paper, ${ }_{1}^{12}$ and/or the Supplementary Materials. We have also created a database in online Harvard Dataverse at https://doi.org/10.7910/DVN/ QOMQK4 about the employed data in this study. Additional data related to this paper may be requested from the authors.

\section{CODE AVAILABILITY}

The codes relevant to this paper may be requested from the first and second authors.

\section{ACKNOWLEDGEMENTS}

We thank Upmanu Lall and William B. Rossow for their constructive suggestions and remarks. This study was supported by the U.S. Department of Energy Early CAREER Award No. DE-SC0018124 for N.D., Hong Kong University of Science and Technology (HKUST) internal fund Z0488, R9392, and IGN16EG06 for M.L. R.P. acknowledges support from the Portuguese Foundation for Science and Technology (Fundação para a Ciência e Tecnologia, FCT) under references UID/BIA/00329/2019 and UID/EEA/ 50008/2019, and Meteoceanics research project MR-220617 "Mathematical Physics and Predictability of Complex Coevolutionary Systems". We would like to sincerely thank the anonymous reviewers for providing us with constructive suggestions and detailed and insightful comments that improved the manuscript.

\section{AUTHOR CONTRIBUTIONS}

N.N., N.D. and M.L. initiated the study. N.N. carried out the data analysis and conducted the experiments. M.L. contributed to the development of the TMEs analysis. N.D. developed the network inference framework. R.P. provided scientific expertise in ocean-atmospheric physics to shed light on the underlying geophysical mechanisms. N.N., N.D., M.L. and R.P. contributed to the discussion and interpretation of the results.

\section{ADDITIONAL INFORMATION}

Supplementary information accompanies the paper on the npj Climate and Atmospheric Science website (https://doi.org/10.1038/s41612-019-0076-6).

Competing interests: The authors declare no competing interests.

Publisher's note: Springer Nature remains neutral with regard to jurisdictional claims in published maps and institutional affiliations.

\section{REFERENCES}

1. Merz, B., Kreibich, H., Schwarze, R. \& Thieken, A. Review article "assessment of economic flood damage". Nat. Hazards Earth Syst. Sci. 10, 1697 (2010).

2. Ward, P., Kummu, M. \& Lall, U. Flood frequencies and durations and their response to El-Nino southern oscillation: global analysis. J. Hydrol. 539, 358-378 (2016).

3. Najibi, N. \& Devineni, N. Recent trends in the frequency and duration of global floods. Earth Syst. Dyn. 9, 757-783 (2018).

4. Javelle, P., Ouarda, T. B. \& Bobée, B. Spring flood analysis using the floodduration-frequency approach: application to the provinces of Quebec and Ontario, Canada. Hydrol. Process. 17, 3717-3736 (2003).

5. Webster, P., Toma, V. E., \& Kim, H.-M. Were the 2010 Pakistan floods predictable?. Geophys. Res. Lett. 38, 1-5 (2011).

6. Pui, A., Lal, A., \& A. Sharma, A. How does the interdecadal Pacific oscillation affect design floods in Australia? Water Resour. Res. 47, 1-13 (2011).

7. Gochis, D. et al. The great Colorado flood of September 2013. Bull. Am. Meteorol. Soc. 96, 1461-1487 (2015).

8. Koks, E. E., Bočkarjova, Md, Moel, H. \& Aerts, J. C. Integrated direct and indirect flood risk modeling: development and sensitivity analysis. Risk Anal. 35, 882-900 (2015).

9. Schröter, K., Kunz, M., Elmer, F., Mühr, B., \& Merz, B. What made the June 2013 flood in Germany an exceptional event? a hydro-meteorological evaluation. Hydrol. Earth Syst. Sci. 19, 309-327 (2015).

10. Haraguchi, M. \& Lall, U. Flood risks and impacts: a case study of Thailand's floods in 2011 and research questions for supply chain decision making. Int. J. Disaster Risk Reduct. 14, 256-272 (2015). 
11. Vahedifard, F., AghaKouchak, A., Ragno, E., Shahrokhabadi, S. \& Mallakpour, I. Lessons from the Oroville Dam. Science 355, 1139-1140 (2017).

12. Najibi, N., Devineni, N. \& Lu, M. Hydroclimate drivers and atmospheric teleconnections of long duration floods: an application to large reservoirs in the Missouri River Basin. Adv. Water Resour. 100, 153-167 (2017).

13. Merz, R., \& Blöschl, G. A process typology of regional floods. Water Resour. Res. 39, 1-20 (2003).

14. Johnson, F. et al. Natural hazards in Australia: floods. Clim. Change 139, 21-35 (2016).

15. Pathiraja, S., Westra, S., \& Sharma, A. Why continuous simulation? The role of antecedent moisture in design flood estimation. Water Resour. Res. 48, 1-15 (2012).

16. Dettinger, M., Redmond, K. \& Cayan, D. Winter orographic precipitation ratios in the Sierra Nevada-Large-scale atmospheric circulations and hydrologic consequences. J. Hydrometeorol. 5, 1102-1116 (2004).

17. Leung, L. R., Qian, Y. \& Atmospheric, Y. rivers induced heavy precipitation and flooding in the western us simulated by the wrf regional climate model. Geophys. Res. Lett. 36, 3 (2009).

18. Lu, M., Lall, U., Schwartz, A. \& Kwon, H. Precipitation predictability associated with tropical moisture exports and circulation patterns for a major flood in France in 1995. Water Resour. Res. 49, 6381-6392 (2013).

19. Nakamura, J., Lall, U., Kushnir, Y., Robertson, A. W. \& Seager, R. Dynamical structure of extreme floods in the U.S. midwest and the United Kingdom. J. Hydrometeorol. 14, 485-504 (2013).

20. Ralph, F. M., et al Flooding on California's Russian River: Role of atmospheric rivers. Geophys. Res. Lett. 33, 1-5 (2006).

21. Rex, D. F. Blocking action in the middle troposphere and its effect upon regional climate. Tellus 2, 275-301 (1950).

22. Barriopedro, D., García-Herrera, R., Lupo, A. R. \& Hernández, E. A climatology of Northern Hemisphere blocking. J. Clim. 19, 1042-1063 (2006).

23. García-Herrera, R. \& Barriopedro, D. Northern Hemisphere snow cover and atmospheric blocking variability. J. Geophys. Res. 111, 1-16 (2006).

24. Hirschi, J. J. M. \& Sinha, B. Negative NAO and cold Eurasian winters: how exceptional was the winter of 1962/1963? Weather 62, 43-48 (2007).

25. Perdigão, R. A. P., Pires, C. A. L., \& Hall, J. Synergistic dynamic theory and predictability of complex coevolutionary systems: Disentangling nonlinear spatiotemporal controls on precipitation. Dynamical Systems (math.DS); Atmospheric and Oceanic Physics (physics.ao-ph). https://arxiv.org/abs/1611.03403 (2016).

26. Perdigão, R. A. P. Independent component analysis of the low frequency geopotential Height field and its relevance to precipitation regimes over the EuroAtlantic region. Dissertation in Geophysical Sciences - Meteorology and Oceanography, Department of Physics, Faculty of Sciences, University of Lisbon, Portugal (2004)

27. Houze, R. A. Jr, Rasmussen, K. L., Medina, S., Brodzik, S. R. \& Romatschke, U. Anomalous atmospheric events leading to the summer 2010 floods in Pakistan Bull. Am. Meteorol. Soc. 92, 291-298 (2011).

28. Wang, S. Y., Hakala, K., Gillies, R. R. \& Capehart, W. J. The Pacific quasi-decadal oscillation (QDO): an important precursor toward anticipating major flood events in the Missouri River Basin? Geophys. Res. Lett. 41, 991-997 (2014).

29. Petersen, W. A. et al. Mesoscale and radar observations of the Fort Collins flash flood of 28 July 1997. Bull. Am. Meteorol. Soc. 80, 191-216 (1999).

30. Blöschl, G., Nester, T., Komma, J., Parajka, J. \& Perdigão, R. A. P. The June 2013 flood in the Upper Danube Basin, and comparisons with the 2002, 1954 and 1899 floods. Hydrol. Earth Syst. Sci. 17, 5197-5212 (2013).

31. National Research Council. The Missouri River Ecosystem: Exploring the Prospects for Recovery. (The National Academies Press, Washington, DC, 2002).

32. Brakenridge, G. R. Global active archive of large flood events, Dartmouth Flood Observatory, University of Colorado. http://floodobservatory.colorado.edu/index. html (2010).
33. Grams, C. M., Binder, H., Pfahl, S., Piaget, N. \& Wernli, H. Atmospheric processes triggering the central European floods in June 2013. Nat. Hazards Earth Syst. Sci. 14, 1691-1702 (2014)

34. Hoskins, B. J. \& Pedder, M. A. The diagnosis of middle latitude synoptic development. Q. J. R. Meteorol. Soc. 106, 707-719 (1980).

35. Paltan, $\mathrm{H}$., et al Global floods and water availability driven by atmospheric rivers. Geophys. Res. Lett. 44, 10387-10395 (2017).

36. Knippertz, P. \& Wernli, H. A lagrangian climatology of tropical moisture exports to the Northern Hemispheric extratropics. J. Clim. 23, 987-1003 (2010).

37. Helfand, H. M. \& Schubert, S. D. Climatology of the simulated Great Plains lowlevel jet and its contribution to the continental moisture budget of the United States. J. Clim. 8, 784-806 (1995).

38. Tang, Y., et al. Future changes in the climatology of the Great Plains low-level jet derived from fine resolution multi-model simulations. Sci. Rep. 7, 1-10 (2017).

39. Lu, M., \& Lall, U. Tropical moisture exports, extreme precipitation and floods in Northeastern US. Earth Sci. Res. 6, 91-111 (2017).

40. Wise, E. K., Woodhouse, C. A., McCabe, G. J., Pederson, G. T. \& St-Jacques, J. M. Hydroclimatology of the Missouri River Basin. J. Hydrometeorol. 19, 161-182 (2018).

41. Lu, M., Lall, U., Robertson, A. W. \& Cook, E. Optimizing multiple reliable forward contracts for reservoir allocation using multi-time scale streamflow forecasts. Water Resour. Res. 53, 2035-2050 (2017).

42. Knippertz, P., Wernli, H. \& Gläser, G. A global climatology of tropical moisture exports. J. Clim. 26, 3031-3045 (2013).

43. Dee, D. P. et al. The ERA-Interim reanalysis: Configuration and performance of the data assimilation system. Q. J. R. Meteorol. Soc. 137, 553-597 (2011).

44. Wernli, B. H. \& Davies, H. C. A Lagrangian-based analysis of extratropical cyclones. I: The method and some applications. Q. J. R. Meteorol. Soc. 123, 467-489 (1997).

45. Lu, M. \& Hao, X. Diagnosis of the tropical moisture exports to the mid-latitudes and the role of atmospheric steering in the extreme precipitation. Atmosphere 8 256 (2017).

46. Kistler, R. et al. The NCEP-NCAR 50-year reanalysis: Monthly means CD-ROM and documentation. Bull. Am. Meteorol. Soc. 82, 247-267 (2001)

47. Gershunov, A., Shulgina, T., Ralph, F. M., Lavers, D. A. \& Rutz, J. J. Assessing the climate-scale variability of atmospheric rivers affecting western North America. Geophys. Res. Lett. 44, 7900-7908 (2017).

48. Nayak, M. A. \& Villarini, G. A long-term perspective of the hydroclimatological impacts of atmospheric rivers over the central United States. Water Resour. Res. 53, 1144-1166 (2017).

49. Gelman, A., \& Hill, J. Data Analysis Using Regression and Multilevel/Hierarchical Models (Cambridge University Press, New York, USA, 648, 2007).

50. Plummer, M. rjags: Bayesian Graphical Models Using MCMC. (R package version 4-6, https://CRAN.R-project.org/package=rjags) (2016).

Open Access This article is licensed under a Creative Commons Attribution 4.0 International License, which permits use, sharing, adaptation, distribution and reproduction in any medium or format, as long as you give appropriate credit to the original author(s) and the source, provide a link to the Creative Commons license, and indicate if changes were made. The images or other third party material in this article are included in the article's Creative Commons license, unless indicated otherwise in a credit line to the material. If material is not included in the article's Creative Commons license and your intended use is not permitted by statutory regulation or exceeds the permitted use, you will need to obtain permission directly from the copyright holder. To view a copy of this license, visit http://creativecommons. org/licenses/by/4.0/.

(c) The Author(s) 2019 